SUPPORTING NEW PRODUCT LAUNCHES WITH SOCIAL MEDIA

COMMUNICATION AND ONLINE ADVERTISING: SALES VOLUME AND

PROFIT IMPLICATIONS

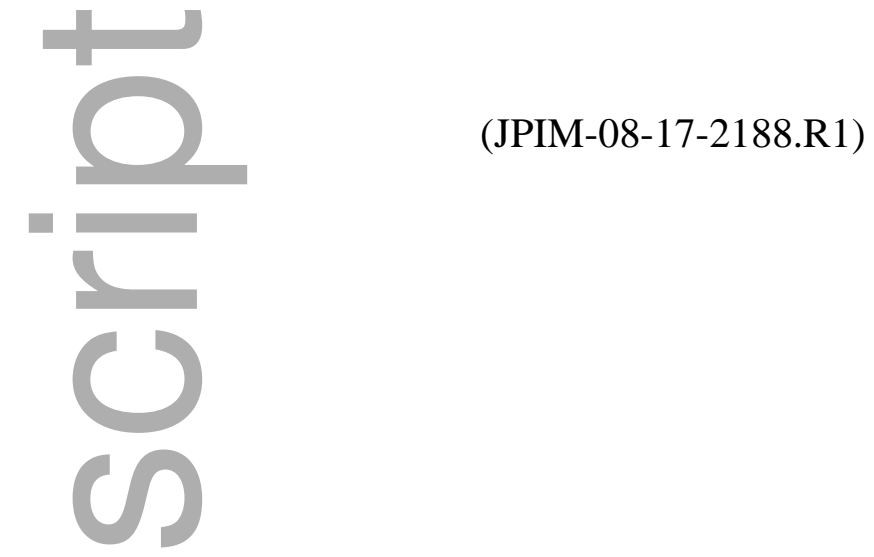

Richard L. Gruner, Arnd Vomberg, Christian Homburg, \& Bryan A. Lukas

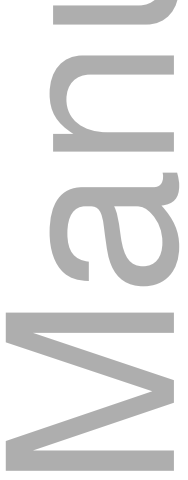

Revised: September 2018

Richard L. Gruner is Senior Lecturer in Marketing, UWA Business School, University of Western Australia, Australia (e-mail: richard.gruner@uwa.edu.au), and University Associate, Faculty of Humanities, Curtin University, Australia. Arnd Vomberg is Assistant Professor for Empirical Research Methods, University of Mannheim, Germany (e-mail:

arnd.vomberg@bwl.uni-mannheim.de).Christian Homburg is Professor of Business Administration and Marketing, University of Mannheim, Germany (e-mail:

homburg@bwl.uni-mannheim.de), and Distinguished Professorial Fellow, Alliance

This is the author manuscript accepted for publication and has undergone full peer review but has not been through the copyediting, typesetting, pagination and proofreading process, which may lead to differences between this version and the Version of Record. Please cite this article as doi: 10.1111/jpim.12475

This article is protected by copyright. All rights reserved 
Manchester Business School, University of Manchester, United Kingdom. Bryan A. Lukas is

Professor of Marketing, Alliance Manchester Business School, University of Manchester, United Kingdom (e-mail: bryan.lukas@manchester.ac.uk), and Professorial Fellow, Department of Management and Marketing, University of Melbourne, Australia.

Address correspondence to: Richard L. Gruner, University of Western Australia, Business School, Crawley, Western Australia, Australia. E-mail: richard.gruner@uwa.edu.au.

\section{Biographical Sketches}

Richard L. Gruner, Ph.D., is a Senior Lecturer in Marketing at the University of Western Australia Business School and a University Associate at Curtin University, Australia. His research interests include digital marketing, operations and IT management, and sustainable supply chain management. He has published in journals such as Journal of the Academy of Marketing Science, European Journal of Information Systems, and International Journal of Operations and Production Management.

Arnd Vomberg, Ph.D., is Assistant Professor for Empirical Research Methods at the Department of Marketing \& Sales at the University of Mannheim, Germany. His main research interests include the marketing-HR-interface, sales and customer relationship management, and e-commerce. His research has been published in journals such as Strategic Management Journal and Journal of the Academy of Marketing Science.

Christian Homburg, Ph.D., is Professor of Marketing, Chairman of the Department of Marketing \& Sales at the University of Mannheim, Germany, and Distinguished Professorial Fellow at the University of Manchester, United Kingdom. His research interests include marketing strategy, sales management, and business-to-business marketing. He has published in journals such as Journal of Marketing, Journal of Marketing Research, Journal of Consumer Research, Strategic Management Journal, Journal of the Academy of Marketing Science, International Journal of Research in Marketing, and Journal of Product Innovation Management. 
Bryan A. Lukas, Ph.D., is Professor of Marketing and Associate Head of Research at the University of Manchester's Alliance Manchester Business School, United Kingdom. He is also Honorary Fellow at the University of Melbourne, Australia. His main research interests are in the filed of marketing management and strategy, with a particular focus on brands and new products. He has published in journals such as Journal of Marketing, Journal of Management, Journal of the Academy of Marketing Science, Journal of Service Research, and Journal of Retailing.

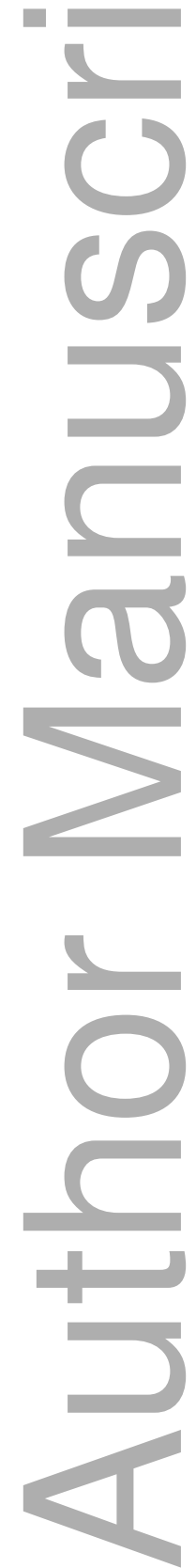


DR. RICHARD L. GRUNER (Orcid ID : 0000-0002-5176-8584)

PROF. CHRISTIAN HOMBURG (Orcid ID : 0000-0002-3584-9181)

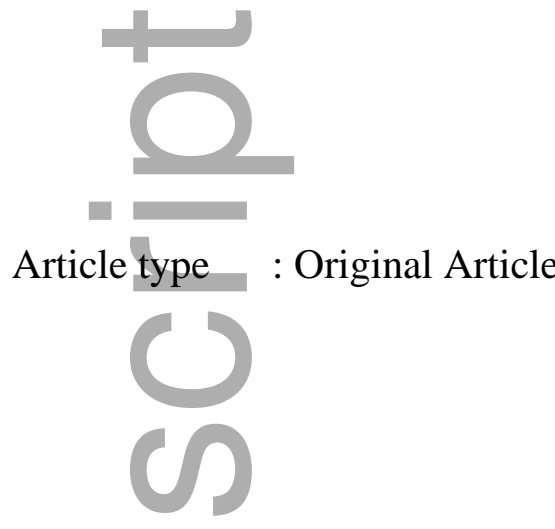

\title{
SUPPORTING NEW PRODUCT LAUNCHES WITH SOCIAL MEDIA COMMUNICATION AND ONLINE ADVERTISING: SALES VOLUME AND PROFIT IMPLICATIONS
}

\begin{abstract}
The question of how important firms' investments in digital communication formats are for the commercial success of new products remains unexplored in the product innovation management literature. Drawing on reactance theory, the authors examine the extent to which investments in social media communication and online advertising are related to the sales volume and profits of new products within six months of being launched. Using dyadic survey data, an analysis of new products launched by 122 consumer durable goods firms reveals that sales volume and profits of new products are associated with (1) social media communication in a positive but diminishing shape, and (2) online advertising in an inverted U-shape. Further analyses show that those curvilinear relationships are steeper for social media communication and flatter for online advertising at respective (1) higher levels of customer product involvement and (2) lower levels of product superiority. The results imply that there is an optimal level of investment in social media communication and online advertising, with the optimum dependent on a new product's consumer involvement and superiority levels.
\end{abstract}

\section{Practitioner Points}

- Digital communications can drive the sales volume and profits of newly launched consumer durable goods, with social media communication (e.g., video-sharing on YouTube and brand communities on Facebook), on average, being more effective than online advertising (e.g., display advertising and search engine advertising).

- It is possible to over-invest in both social media communication and online advertising; while consumers can resent both digital communications formats, they tend to react more 
strongly against online advertising to the extent that sales volumes and profits can fall.

- Product characteristics should be considered when investing in digital communications to support a new product's launch, since they define the optimal level of investments in social media communication and online advertising.

- The more consumer-involving a new product is, the higher the level of investments in online advertising required to achieve certain sales volume and profit targets within the first six months of a product's launch, while social media communication investments can be wound back to meet the same targets. And the less superior a new product is, the more investments in social media communication and online advertising are required to achieve sales volume and profit targets.

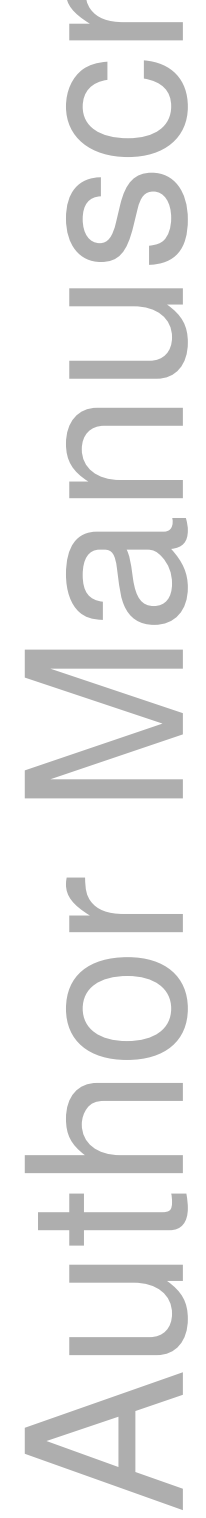




\section{Introduction}

Research studies in the field of product innovation management show that a well-planned and executed product launch strategy greatly improves new product success (e.g., Di Benedetto, 1999; Heidenreich and Kraemer, 2016; Hultink et al. , 1997; Roberts and Candi, 2014). A

number of those studies highlight the important role that communication investments play in new product launch strategies (e.g., Di Benedetto, 1999; Hultink and Robben, 1999). However, the studies' focus has been on traditional communication formats, including advertising via printed media and TV channels as well as publicity using news outlets and public relations agencies. A review of the literature (examples of which are in Table 1) shows that research into the role of investments in digital communications for new product success is limited, despite expectations that such investments will be a "game-changing opportunity" for the commercialization of new products (Roberts and Piller, 2016, p. 42) and reports that digital communications account for more than $40 \%$ of large companies' communications budgets (HBR, 2017). Substantive research questions, therefore, remain unaddressed in the literature, such as whether there are variations in the extent to which new product success is related to investments in different digital communication formats as well as whether and how boundary conditions influence the relationships.

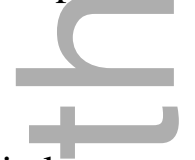
----Please insert Table 1 here----

Digital communications first emerged in the early 1990s, with online advertising being the primary digital communication format. Online advertising consists of digital advertising on web portals (e.g., display advertising) and web browsers (e.g., search engine advertising). Following the arrival of mainstream social media in the early 2000s, social media communication has become the fastest-growing digital communications format for firms (Statista, 2018). Social 
media communication consists of social sharing platforms (e.g., video-sharing on YouTube) and an active social network presence (e.g., brand communities on Facebook).

One of the earliest examples of a product launch based on digital communications is Ford Motor Company's 2010 re-launch of the Ford Fiesta auto in the United States, which combined online advertising and social media (Spenner, 2010). As part of the social media component of the launch campaign, Fiesta enthusiasts were encouraged to create and share original social communication content by blogging and uploading video content. Largely due to the success of the Fiesta, Ford achieved the fastest auto sales growth of any American auto brand among the Millennials demographic between 2000 and the Fiesta's model replacement three years later (Buss, 2013). Perhaps one of the most well-known examples of digital communications use is the launch of Dollar Shave Club's disposable razors. After relying on bloggers for the first six months of the razors' launch, breakthrough market acceptance was reached in a matter of days with the uploading of what has been called a "cheeky" video on YouTube in 2012 that went viral (Dahl, 2013). Supported by online advertising and complementary product introductions, Dollar Shave Club sales reached \$200m before the company was acquired by Unilever in 2016 (Daneshkhu, 2016). ${ }^{1}$

While it is reasonable to assume that new product success is related to investments in both social media communication and online advertising, the extent and shape of the two relationships, and potential relationship contingencies, have not been examined. Our objective is to provide first insights into those unexplored aspects of digitally promoted new product introductions - an objective motivated by a growing tendency among managers to (1) prioritize communication investments during the launch phase of their new products (e.g., Barroso and Llobet, 2012) and (2) shift their communications budgets toward digital formats (Statista, 2018). 
New product success is indicated in this study by sales volume and profit levels because these two factors are important indicators of a product's commercial success. And investments in social media communication and online advertising are reflected in terms of financial and human resource commitments, since both types of resources are required for achieving social network presence and online advertising exposure.

The article's primary contributions to the product innovation management literature are threefold. This is the first reported study to disaggregate how the success of new products is linked to digital communication investments by differentiating between social media communication and online advertising investments, which opens the literature to a new perspective on why new product success can vary (e.g., Prins and Verhoef, 2007). Second, reactance theory (Brehm, 1966) is introduced to the product innovation management literature, which is a social psychological theory that can be used to describe and explain consumers' resistance to firms' attempts to influence their behaviors. Used as this study's theoretical foundation, reactance theory facilitates a deeper understanding of the complex mechanisms underlying the relationship between digital communication investments and new product success. Reactance theory also offers a theoretical basis for future research into questioning the predominantly positive and linear conceptualizations of communications effects prevalent in the broader literature. Finally, the importance of two contingency factors for explaining new product success is demonstrated by showing that the way in which a new product's commercialization is related to social media communication and online advertising is contingent on a new product's superiority and product involvement.

\section{Research Overview}

This study is couched in the product innovation management literature within the area of new 
product success. That literature highlights investments in communications as an important success driver (e.g., Di Benedetto, 1999; Hultink and Robben, 1999), especially during the launch phase of new products (e.g., Horsky and Simon, 1983).

A review of the relevant background literature shows that potential non-linear effects of communications have rarely been considered, especially not in relation to new product success (e.g., Godfrey, Seiders, and Voss, 2011). Further, there is limited research on the extent to which communications-induced product effects might be a function of situational factors. This is notable because it is implausible that communication effects occur in isolation, independent of boundary conditions. Further, new product studies concerned with online advertising are largely absent. Table 1 provides a selective summary of the reviewed literature.

Moreover, reflecting on the broader literature beyond Table 1, even among studies concerned with how the performance of established products ${ }^{2}$ are associated with digital communications, we only are aware of very few studies—-such as those by Danaher and Dagger (2013); Dinner, Van Heerde, and Neslin (2014); De Haan, Wiesel, and Pauwels (2016); Kumar et al. (2016); Srinivasan, Rutz, and Pauwels (2016) — that have examined product sales or profit effects; and they are, without exception, single-firm analyses and treat digital communications as an aggregate construct without distinguishing between different digital communication formats.

\section{Conceptual Background}

The baseline expectations expressed in this article are that firms' investments in social media communication and online advertising are associated with new product success, and that these associations are both non-linear and contingent on boundary conditions. The theoretical basis for those expectations is reactance theory (Brehm, 1966). The theory explains that firms' attempts to influence consumers can generate a motivational state of reactance, or resistance, in which 
consumers' responsiveness to communication messages diminishes, or in which consumers decide to respond, but negatively in the form of a backlash to messages' content (e.g., Miron and Brehm, 2006). Reactance is expected to set in when consumers feel they are being told what to do in a manner they perceive to be limiting their choices among perceived alternatives. The extent to which consumers value their free choice is a determinant of their level of reactance (e.g., Clee and Wicklund, 1980). An expression of reactance behavior is when consumers seek to restore their freedom of choice by intentionally not buying, or by persuading other consumers to avoid a promoted product. The existence of such behavior has been documented by Godfrey, Seiders, and Voss (2011) and Robertson and Rossiter (1974), among others.

For the boundary conditions of digital communication effects on new product success, we concentrate on product involvement and product superiority. Product involvement is the extent to which a product is engaging and plays an important role in consumers' lives and, therefore, also reflects how carefully chosen and thoughtfully purchased a product is (e.g., Laurent and Kapferer, 1985). Product superiority is the excellence of a product in terms of its features (e.g., aesthetics and functions), consumer benefits (e.g., productivity and image), and technology (e.g., technical components and software) (e.g., Lee and O'Connor, 2003). A clear indication of superiority is whether a product is one or more generations ahead of all other competing offerings, such as Tesla automobiles among electric vehicles worldwide in 2017.

Our interest in product involvement is motivated by the possibility that the amount of thought consumers give to a communication message about a product—and, hence, their potential responses to that message - might depend on how much involvement the type and nature of the product fundamentally requires from consumers (e.g., Petty, Cacioppo, and Schumann, 1983). The interest in product superiority stems from studies suggesting that 
consumer responses to a given message are also likely to depend on how intrinsically apprehensive consumers are toward promoted products that are perceived to far exceed product specifications and performance standards typically available (e.g., Talke and O'Connor, 2011).

To structure our theoretical reasoning in support of the hypothesized relationships discussed in the next section, we distinguish between social media communication and online advertising (-

in terms of (1) communication initiation, (3) communication control, and (3) communication intrusiveness. As discussed in the hypothesis development section, differences across those three characteristics likely result in different product success outcomes. Table 2 summarizes the differences.

\section{----Please insert Table 2 here----}

Briefly, social media communication and online advertising can be delineated in terms of each media's communication initiation, or the source of promotional message initiation. This initiation characteristic distinguishes online advertising as firm-initiated, and social media communication as not only firm-initiated, but also consumer-initiated (for instance, when consumers request new product information on social media platforms) (e.g., Winer, 2009). In terms of communication control, online advertising allows firms to retain full control over advertising messages by relying on paid content (e.g., banner advertising), while social media communication combines owned (e.g., a firm's website content) and earned content (e.g., word of mouth [WOM]), thereby partially relinquishing control over communication messages (e.g., Kaplan and Haenlein, 2010). Finally, communication intrusiveness, or the degree to which communication interrupts a consumer's task performance, characterizes online advertising as intrusive, and social media advertising as unintrusive.

\section{Hypothesized main effects}


Figure 1 summarizes the conceptual model. Below, the hypothesized main effects are discussed, followed by the moderator effects.

----Please insert Figure 1 here----

\section{New product success and investments in digital communications}

New product success research shows that consumers differ in their product adoption behaviors (e.g., Rogers, 2003); a key reason being that consumers usually have different levels of familiarity with the novelty of new products and vary in the product benefits they require (e.g., Heidenreich and Kraemer, 2016). To respond to those differences, studies have shown the importance of targeted, differentiated communications during the launch of new products (e.g., Prins and Verhoef, 2007; Talke and Hultink, 2010). Both social media and online advertising are conducive to those targeted communication needs.

Specifically, with social media communication, companies can initiate and facilitate interactive conversations between consumers and marketers, enabling marketers to respond in a targeted way to consumers' doubts and questions about new products on a one-on-one basis. With online advertising, companies can track consumers on the basis of their profiles, previous purchases, and other online behaviors to provide highly targeted advertising messages (e.g., Goldfarb and Tucker, 2011). Needs-specific product information also can be provided via embedded links. Overall, both social media communication and online advertising are suited to targeting consumers who have different product concerns and adoption reasons (Talke and O’Connor, 2011; Talke and Snelders, 2013). Thus, social media communication and online advertising can significantly contribute to a new product's success in the market.

The discussed success effects, however, are only likely to occur to a certain extent, after which reactance effects can be expected to set in. Because reactance effects likely differ for 
social media communication and online advertising, we discuss the communications formats separately, beginning with social media communication in the next sub-section.

\section{Social media communication}

As outlined, investments in social media communication have a positive effect on new product success; yet, we expect this effect to weaken at higher levels of communication investments.

With social media communication companies remain, to a certain extent, in control of their communication intensity (see Table 2), and may succumb to the temptation of promoting a given product too strongly (e.g., through frequent tweets about the product, or being overly dominant in online product-discussion forums). At such high levels of investment in social media communication, social media exchanges can be intense, and even suppress other subject matters (Piskorski, 2014). In turn, it is plausible for consumers to find themselves topic-saturated. Also, consumers may develop the view that their product opinions and choices are being overly influenced and that the engaging firm has overstretched its network-member rights, thereby becoming intrusive (see Table 2). Consequently, consumers can develop a motivational state of reactance, corresponding with the possibility that consumers instinctively change the direction of their social media conversations, or change topics altogether. Effectively, the focal new product ceases to benefit from being promoted on social media, pointing to a positive, but diminishing, social media effect. Summarizing our reasoning, we hypothesize:

$\mathrm{H}_{1}$ : A positive but diminishing relationship exists between new product success and investments in social media communication.

\section{Online advertising}

In contrast, for online advertising, not only can a weakening of communication effectiveness be expected but an effect-reversal, resulting in an inverted U-shaped relationship between investments in online advertising and new product success. In terms of communication initiation 
and intrusiveness, targeted consumers are involuntarily approached (see Table 2). However, communications research shows that consumers prefer to perform online tasks without such interruptions (e.g., Cho and Cheon, 2004; Goldfarb and Tucker, 2011) and can question tailored advertising on the grounds of privacy concerns (e.g., Turow et al., 2009). The involuntary nature of online advertising, then, has the potential to result in higher reactance levels than social media communication. "Banner blindness"—a tendency to ignore online advertising — and the implementation of ad-blocker software as relief measures are indicators of the strength of reactance that online advertising can evoke. At very high levels of reactance, it is also plausible that consumers adopt retaliatory behaviors and turn against the new product, which negatively affects its market success. Negative WOM is an example of retaliation and can take the form of actively discouraging other consumers from purchasing the advertised new product.

Consequently, we expect two countervailing effects of online advertising on new product success, leading to an inverted U-shaped relationship ${ }^{3}$. On the one hand, investment in online advertising stimulates awareness and helps generate a preference for the new product. On the other hand, we expect reactance to escalate as investments in online advertising increase to very high levels, eventually outweighing the positive effects of online advertising. Thus, we hypothesize the following:

$\mathrm{H}_{2}$ : An inverted $\mathrm{U}$-shaped relationship exists between new product success and investments in online advertising.

\section{Hypothesized moderator effects}

\section{New product suecess and moderating effects of product superiority}

Social media communication. We develop two competing predictions for the moderating effect of product superiority on the relationship between social media communication and new product success. One prediction is that the positive association between social media communication and 
new product success are enhanced for superior products, which is explained first.

Consumers may consider the purchase of highly superior products to be risky because those products can imply high learning efforts — such as having to understand new ways of using a product - and potentially require behavior and attitude changes (Dahl and Hoeffler, 2004; Talke and O'Connor, 2011). Consumers, therefore, may appreciate the social media facilitated option of initiating a conversation with the product-introducing firms and other consumers to learn more about these products (see Table 2). Those facilitated exchanges may significantly decrease consumers' perceived risk levels and allow for a more thorough and trusted assessment of whether a new product should be adopted (Parry and Kawakami, 2014; Ram and Sheth, 1989). Social media communication, in the form of videos for instance, can help consumers visualize how to use superior products as can dialogues between consumers on firm-hosted social media platforms (e.g., Parry, Kawakami, and Kishiya, 2012). This can help lower perceived learning burdens and encourage consumers' favorable product evaluations (e.g., Dahl and Hoeffler, 2004), thus ultimately strengthening the relationship between social media investments and new product success.

Moreoyer, reactance effects potentially associated with social media investments might be less prevalent for superior products. Clee and Wicklund (1980) argue that reactance effects tend to be lower if communication attempts are perceived to be helpful and informative. Edwards, Li, and Lee (2002) make similar observations. Since consumers may like to obtain additional information about superior products, they are likely to appreciate companies' social media communication investments, thus reducing the likelihood of consumer reactance to new product communications via social media. We hypothesize as follows:

$\mathrm{H}_{3 \mathrm{a}}$ : Product superiority steepens the relationship between new product success and investments in social media communication. 
An opposing prediction is plausible, however, whereby the positive effects of social media communication are weakened for superior new products. Research indicates that consumers not only feel uncertain about new products promoted as superior, but may also resist having to potentially re-learn how to use a superior product, given the often required behavior and attitude changes necessary to take full advantage of what makes a product superior (Heidenreich and Handrich, 2015; Ram and Sheth, 1989). This reasoning forms the basis for a plausible alternative prediction.

Resistance to superior products has been discussed in detail by Heidenreich and Handrich (2015) and may take the shape of blocking out information. Similar to "banner blindness", a situation of "social media blindness" toward a firm's messages might arise for superior products (Morgan, 2015), which can undermine social media communications' product promoting effects (Roberts and Candi, 2014). WOM engagements may also be lower, generating less awareness for new products (Libai, Muller, and Peres, 2013).

It is also possible that reactance effects increase. Superior products and their implied changes can serve as "stressors" for consumers (Heidenreich and Handrich, 2015); they can be perceived to be disruptive to established and familiar product usage patterns. Reversing the reasoning for $\mathrm{H}_{3 \mathrm{a}}$ above, therefore, targeted attempts by firms to be helpful and informative in relation to new products may not be welcome. Consumers might not wish to obtain additional information about superior products and, therefore, fail to appreciate companies' activity on social media platforms. In turn, an increasing likelihood of reactance to investments in social media communication is also possible. Hence, we provide an alternative hypothesis:

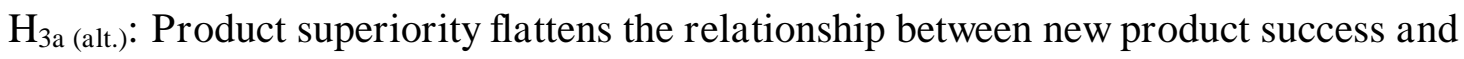
investments in social media communication.

Online advertising. A case for the moderating effect of product superiority on the 
relationship between online advertising and new product success builds on our reasoning for $\mathrm{H}_{2}$. The highly targeted product messages that online advertising is capable of ( $\mathrm{see}_{2}$ ) will also benefit the promotion of superior new products. Where superiority will be most influential is at the point where reactance is likely to set in, and we predict that the level of reactance discussed for $\mathrm{H}_{2}$ will be amplified corresponding with the level of superiority of the new product.

Specifically, while product information on superior products can be of interest to consumers, the intrusive nature of online advertising (see Table 2) along with the conceivably disruptive capacity of established and familiar product usage patterns associated with superior new products discussed earlier, have the potential to result in higher reactance levels than if a product is less superior. Therefore, at higher levels of product superiority, a strengthening of the negative effect pertaining to the relationship between investment in online advertising and new product success is expected. Stated succinctly, the inverted U-shaped relationship between investment in online advertising and new product success becomes steeper. ${ }^{4}$ More formally:

$\mathrm{H}_{3 \mathrm{~b}}$ : Product superiority steepens the inverted U-shaped relationship between new product success and investments in online advertising.

The apex of the U-shaped relationship may also shift. Since the direction in which the turning point could move is theoretically unclear, we do not provide a prediction, but undertake an empirical exploration, which we describe later.

\section{New product success and moderating effects of product involvement}

Social media communication. Consumers of highly involved products tend to have high product information needs. Social media communication is conducive to consumers accessing information required from firms because social media enables consumers to initiate, follow, and actively participate in firms' product-related communications at their discretion (see Table 2). Social media communication is also conducive to the needs of consumers to interact with each 
other about products they feel involved with. Westbrook (1987) found product involvement to be a central motivation for consumers to spread WOM, and Füller, Matzler, and Hoppe (2008) found that product involvement leads to increased participation on social media. High product involvement, thus, enhances the product-promotional advantages of investments in social media communication and, therefore, the relationship between investments in social media communication and new product success.

The onset of reactance at higher levels of investment in social media communication, which we discussed earlier, may also be reduced by high-involvement products. This possibility is supported by Lee, Kim, and Sundar (2015) who observe that product involvement lowers messages' perceived intrusiveness. It follows that consumers— since they are likely to harbor a preference for information about products they feel involved with—are likely to appreciate companies' social media communication investments, thus reducing the likelihood of reactance setting in at high levels of firms' social media investments. Thus, we predict the following moderated relationship:

$\mathrm{H}_{4 \mathrm{a}}$ : Product involvement steepens the relationship between new product success and investments in social media communication.

Online advertising. The intrusive nature of online advertising (see Table 2) and the resulting potential to result in higher reactance levels than induced by social media communication has been noted in the discussion leading to $\mathrm{H}_{2}$. However, as we indicated in our reasoning for $\mathrm{H}_{4 a}$, consumers are likely to be open toward product-related communication content to the extent that a promoted product is engaging, and, therefore, requires careful deliberation when considered for purchase. Consequently, consumers may be more inclined to entertain product information via online advertising if the promoted new product is high-involvement, thus raising tolerance levels for online advertising and dampening the discussed onset of reactance linked to the 
characteristics of online advertising. Hence, product involvement is likely to moderate both the positive and negative effects underpinning the hypothesized inverted U-shaped relationship between online advertising and new product success stated in $\mathrm{H}_{2}$. Since reactance effects weaken, the overall shape flattens. We therefore hypothesize:

$\mathrm{H}_{4 \mathrm{~b}}$ : Product involvement flattens the inverted U-shaped relationship between new product success and investments in online advertising.

Since the apex of the inverted U-shaped relationship may shift, but the direction is theoretically unclear, we do not provide a prediction, and instead explore this possibility later in our empirical analysis.

\section{Method}

The hypotheses were tested with a multi-firm, survey-based study exhibiting three important data advantages. First, each new product launch surveyed was accompanied by communication investments in both social media and online advertising, which ensures that the productlaunching firms were competent in the use of both types of digital communications and minimizes the possibility that the data reflect a bias toward one specific communication type. Second, the data enable us to control for traditional advertising effects. Finally, the data sources are dyadic to avoid potential common source bias.

\section{Research setting and design}

Consumer durable goods firms provided the empirical setting for the study. This setting was selected after a review of the trade literature showed that, when launching new products, consumer durable goods firms regularly use digital communications in addition to traditional media channels, such as print and television. Basing the research design on a single industry controls for extraneous sources of variation related to industry type.

To insure analytical validity—given the continuous, rapid advancements in digital advertising 
practice - personal contacts were used to assemble a convenience sample of marketing managers of 15 firms to comment on our proposed methodology. The managers had work experience in the study's empirical setting and agreed to being interviewed over the phone, which lasted 45 minutes on average. ${ }^{5}$

A key recommendation of the consulted managers was to survey products that were new to a firm and its product portfolio in order to account for potential communication spill-over effects that could arise if the focal products were simply new versions or line extensions of firms' existing products. As the assessment period for a new product's sales volume and profits, another recommendation was to focus on a product's first six months of purchase availability - the managerial consensus being that six months after the launch of a new product (1) many firms do not consider a product to be "new" any longer and, hence, communication that is specific to launching a new product is usually phased out; and (2) factors external to the product other than media communications increasingly influence product success, such as competitor responses (for example, in the form of product counter-launches).

For the sample, we relied on public, commercial, and our own databases from which we randomly selected 245 multinational firms that had recently launched a new product with the support of both online advertising and social media communication. After an initial contact to explain the study, all selected firms agreed to be included in the study and to facilitate access to their senior marketing officers for the exogenous variable data and senior accounting or financial officers for the endogenous variable data. This high participation rate indicates strong practitioner interest in the study's research objective. The dual-informant design (1) minimizes the risk of common source bias during the survey procedure and (2) ensures data from highly knowledgeable firm sources - that is, communications data from the marketing function, and 
performance data from the accounting/finance function (see Podsakoff, MacKenzie, and Podsakoff, 2012). After several reminders, 128 firms responded, of which 124 provided matching sets of questionnaires from the marketing and accounting/finance informants—an effective response rate of $51 \%$. Two observations had to be deleted due to missing values resulting in an effective sample of 122 new product launches by firms from the following industries: automotive (32\%), electronics (24\%), other white goods (21\%), sports (17\%), and furniture $(6 \%)$.

\section{Measures}

The measures were designed for primary field data. Available secondary data on investments in social media communication and online advertising is typically financial in nature and, in that case, may distort companies' actual investments in these platforms because such data can only incompletely account for firms' time and human resources invested in maintaining a digital presence. Moreover, secondary data concerning online advertising has its own drawbacks, given that investments in online advertising are usually not only determined by marketers' investment decisions but—due to the prevalence of pay-per-click models in the online advertising industry—also by consumer behavior. Thus, linking observable investments for online advertising to new product success could introduce circular reasoning since more successful campaigns result in higher communication investments (Blake, Nosko, and Tadelis, 2015).

Two questionnaires were developed—one for the independent variables, and one for the dependent variables. The Appendix contains the measurement instruments, which were developed following standard psychometric procedures (e.g., Gerbing and Anderson, 1988). All constructs were measured with reflective scales and most were based on existing items. Respondents were asked to focus on their firm's most recently launched product supported by 
online advertising and online media communication so as to minimize potential selection bias in relation to the unit of analysis.

Dependent variables. New product sales volume and new product profits were used to assess a new product's market performance and financial performance, respectively (e.g., Lee and O’Connor, 2003; Langerak, Hultink, and Griffin, 2008). Both variables assess independent aspects of new product performance and correspond with different firm goals for new products (e.g., Hultink and Robben, 1995). New product sales volume and product profits were measured with three items that require respondents to compare the focal product's sales, and then its profits, relative to the corresponding (1) performance of their firm's other recent new products, (2) performance objective set by the firm for the product, and (3) performance of competing products. Respondents reflected on their focal product until six months after being launched. Various arguments support the choice of relative performance metrics. For one, these metrics have the advantage that the measures are comparable between companies (e.g., Wall et al., 2004). Comparability is important because, although a single industry setting was used, firm and contextual variations remain. Further, relative performance is easy to evaluate by key informants and, although subjective, displays high correlations with objective performance measures (e.g., Richard et al., 2009; Wall et al., 2004). Indeed, Homburg et al. (2012) demonstrate that when reflecting on objective information, key informants provide mostly accurate responses. Finally, relative measures of new product success are widely applied in the literature ensuring comparability of our results (e.g., Langerak, Hultink, and Griffin, 2008).

Independent variables. When gauging investments in online advertising, researchers should recall, as noted above, that pay-per click advertising models are widely used by publishers (e.g., website owners) for online advertising (Blake, Nosko, and Tadelis, 2015). These 
models can distort analyses of online advertising effectiveness that are based exclusively on advertisers' monetary investments in their media campaigns because advertising costs are only incurred if the advertisements are clicked on and, thus, become realized, or actual, promotional exposures. Accordingly, using three scale items, respectively, we assessed a firm's (1) monetary expenditures, (2) staff numbers, and (3) staff hours committed to exposing consumers to promotional content related to a given new product. Survey respondents were required to benchmark their judgements of the three items against their (1) firm's other recent product launches and (2) main competitors' comparable products, thereby producing a double-set of three scale items for our online advertising scale and, in turn, generating six data points. For consistency reasons, the same measurement design for assessing investments in social media communication were employed given that monetary expenditure, staff numbers, and staff hours are equally applicable to a firm's social media activity. A 0-100 response format was used, ranging from "strongly disagree" to "strongly agree". This fine grained rating scale was chosen because prior research illustrates that coarse response formats (such as 1-7) can conceal moderating effects (e.g., Russell and Bobko, 1992); a concern particularly relevant for this study since non-linear effects in combination with moderating effects are examined. ${ }^{6}$

Moderators. Product involvement was assessed by the extent to which a new product was, for consumers, likely to (1) be engaging, (2) play an important role in their life, (3) be carefully chosen, and (4) require thoughtfulness during the purchase. Product superiority measured how superior a product's (1) technology, (2) benefits, (3) and features were for customers.

Control variables. To account for potential performance effects arising from the use of traditional media advertising, investments in traditional media advertising was measured. Communication channel integration was assessed to account for performance effects that might 
arise from integrating campaigns for a product across online, social, and traditional media. Also controlled for was product positioning to account for typical, or common aspects of a product's value proposition. ${ }^{7}$ Adoption difficulties was included to assess consumers' risk perceptions associated with adopting a new product. Employee capabilities was added to assess a firm's employee-specific contributions to the success of a new product. Product introduction timing was assessed to account for how much an early-mover advantage might have contributed to the success of a surveyed new product. Firm size was also controlled for.

\section{Measurement assessment}

To assess the reliability and validity of the measures, a confirmatory factor analysis including all constructs was conducted. The fit of the confirmatory factor model is satisfactory $\left(\chi^{2} /\right.$ d.f. $=$ 2.14 ; root mean square error of approximation $=.10$; standardized root mean square residual $=$ .08 ), and the measures display good psychometric properties, with constructs exceeding the value of . 70 for Cronbach's alpha, .60 for composite reliability, and .50 for average variance extracted (AVE) (see Table 3). One measurement item has an item reliability (IR) lower than 40 $\left(\mathrm{IR}_{\text {Ease-of-use }}=.32\right)$, and one item has a factor loading $(\mathrm{FL})$ under $.70\left(\mathrm{FL}_{\text {Staff numbers }}=.67\right)$.

Favoring conceptual completeness over maximizing internal consistency, both items were retained (see Bagozzi and Yi, 2012; Little, Lindenberger, and Nesselroade, 1999). A robustness check that re-estimated our models, excluding those two items, showed that estimates remain stable. The square root of the AVE for each construct exceeds the highest correlation, thus meeting the Fornell and Larcker (1981) criterionfor discriminant validity (Table 3).

----Please insert Table 3 here-----

\section{Results}

Seemingly unrelated regressions (SUR) were performed to empirically test the hypotheses. 
Given the presence of two dependent variables, ordinary least squares regression may overlook dependencies between the two equations. SUR overcomes that possibility by jointly estimating the two regressions in one system. A significant Breusch-Pagan test justified the choice because the error terms of the regression equations are significantly correlated $\left(\chi^{2}(\right.$ d.f. $=1)=47.355 ; p<$ $.01)$.

Two regression models were estimated for which the results are displayed in Table 4. Results of additional robustness checks are reported in the Web Appendix. First investigated were the main effects of investments in social media communication and online advertising on new products' sales volume $\left(\mathrm{R}^{2}=.62\right)$ and profits $\left(\mathrm{R}^{2}=.52\right)$, and then the interaction terms were added in a second model to observe the respective effects. The increases in $\mathrm{R}^{2}$ are statistically significant $\left(\mathrm{R}^{2}=.67 ; \Delta \mathrm{R}^{2}=.05, \mathrm{p}<.05 ; \mathrm{R}^{2}=.58 ; \Delta \mathrm{R}^{2}=.06, \mathrm{p}<.05\right)$. The sizes of the increases in $\mathrm{R}^{2}\left(\Delta \mathrm{R}^{2}=.05\right.$ and $\left.\Delta \mathrm{R}^{2}=.06\right)$ are in line with prior research (e.g., Aguinis et al., 2005; Champoux and Peters, 1987).

----Please insert Table 4 here-----

\section{Main effects}

An analysis of the hypothesized main effects shows a positive, but diminishing effect (i.e., logarithmic effect) of investments in social media communication on new product sales volume $(\mathrm{b}=.612, \mathrm{p}<.01)$ and new product profits $(\mathrm{b}=.532, \mathrm{p}<.01)$. Hence, $\mathrm{H}_{1}$ is supported.

To analyze the hypothesized inverted U-shaped relationship between investments in online advertising and new product success, three requirements were tested, following Haans, Pieters, and $\mathrm{He}(2015)$. Squared terms were first examined and were found to be negative and significant for new product sales volume $\left(\mathrm{b}_{\text {squared }}=-.001, \mathrm{p}<.01\right)$ and new product profits $\left(\mathrm{b}_{\text {squared }}=-.001, \mathrm{p}\right.$ $<.01)$. Since standardized coefficients are not reported, and the scales of the underlying 
investment levels are fine-grained (0-100), the resulting squared regression coefficients appear small. Nonetheless, as the shape of the inverted U-shaped relationship indicates (Figure A1 in the Appendix), the coefficients are relevant. Next, an examination of whether the inverted U-shaped effect was within the range of the data revealed that the slopes in the new product sales volume $\left(b_{\text {lower }}=.030, \mathrm{p}<.05 ; \mathrm{b}_{\text {upper }}=-.080, \mathrm{p}<.01\right)$ and new product profits $\left(\mathrm{b}_{\text {lower }}=.056, \mathrm{p}<.05 ; \mathrm{b}_{\text {upper }}\right.$ $=-.099, \mathrm{p}<.01)$ regression models are significant in the expected directions. Finally, the level of investments in online advertising $\left(\mathrm{OA}^{*}\right)$ at which point the maximum point is reached for new product sales volume $\left(\mathrm{OA}^{*}=-32.25\right)$ and new product profits $\left(\mathrm{OA}^{*}=-25.56\right)$ was calculated. Since the data were mean-centered, the maximum values are negative; nevertheless, they lie within the observed data range. Overall, the three tests provide strong support for $\mathrm{H}_{2}$. Figure A1 in the Appendix graphically illustrates the inverted U-shaped effect.

\section{Moderating effects}

Social media communication. Results show that product superiority flattens the effect of investments in social media communication on new product sales volume $(b=-.261, p<.01)$ and new product profits $(\mathrm{b}=-.260, \mathrm{p}<.01)$. Thus, $\mathrm{H}_{3 \mathrm{a}(\text { alt. }}$ is supported. Further, product involvement steepens the effect of social media communication on new product sales volume (b $=.390, \mathrm{p}<.01)$ and new product profits $(\mathrm{b}=.403, \mathrm{p}<.01)$. Hence, $\mathrm{H}_{4 \mathrm{a}}$ is supported.

Online advertising. Since a moderating effect on an inverted U-shape relationship can shift the apex and change the curvature, these possibilities were examined for our moderators separately. Figure A2 in the Appendix graphically illustrates those moderating effects.

Panels A and B of Figure A2 display the two curves pertaining to product superiority. We also calculated the shift of the ideal investment level for online advertising and observed that the ideal level shifts to the right as product superiority increases from low to high levels for new 
product sales volume $\left(\mathrm{OA}_{\text {low }}=-36.65 ; \mathrm{OA}_{\text {high }}=-28.03\right)$ and new product profits $\left(\mathrm{OA} *_{\text {low }}=-\right.$ 26.89; $\left.\mathrm{OA}_{\text {high }}=-22.56\right)$. However, only for new product sales volume $\left(\mathrm{b}_{\text {squared }}=-.000, \mathrm{p}<.05\right)$ was a significant steepening of the curve observed; the effect for new product profits is in the expected direction but not significant $\left(b_{\text {squared }}=-.000\right.$, n.s. $)$. Therefore, there is partial support for $\mathrm{H}_{3 \mathrm{~b}}$. We note that, when comparing the two graphs in Panels A and B, investments in online advertising are less effective for superior products.

Panels C and D of Figure A2 graphically illustrate the moderating effects of product involvement and show that ideal investment levels shift to the left when product involvement increases from low to high levels for new product sales volume $\left(\mathrm{OA}^{*}\right.$ low $=-24.70 ; \mathrm{OA}^{*}{ }_{\text {high }}=-$ 35.92) and new product profits $\left(\mathrm{OA}_{\text {low }}=-19.55 ; \mathrm{OA}_{\text {high }}=-26.49\right)$. Moreover, the positive and significant interaction effects with the squared investment levels for new product sales volume $\left(\mathrm{b}_{\text {squared }}=.000, \mathrm{p}<.01\right)$ and new product profits $\left(\mathrm{b}_{\mathrm{squared}}=.000, \mathrm{p}<.01\right)$ indicate that the curve flattens. Thus, $\mathrm{H}_{4 \mathrm{~b}}$ is supported.

\section{Addressing endogeneity}

In addition to the measured control variables, Gaussian copulas was used to model potentially remaining correlations between the assessed digital communication investments and the error term. Gaussian copulas pertain to instrument-free methods, and researchers have applied copulas in a number of recent studies (e.g., Burmester et al., 2015; Datta, Foubert, and Van Heerde, 2015) to model correlations between the endogenous regressors and the error term (Park and Gupta, 2012). Two regressors were added:

$$
\widetilde{S M_{\mathrm{i}}}=\Phi^{-1}\left[H_{S M}\left(S M_{i}\right)\right] \text { and } \widetilde{O A_{\mathrm{i}}}=\Phi^{-1}\left[H_{O A}\left(O A_{i}\right)\right]
$$

where $\Phi^{-1}$ is the inverse of the cumulative distribution function, and $\mathrm{H}_{\mathrm{SM}}(\bullet)$ and $\mathrm{H}_{\mathrm{OA}}(\bullet)$ 
respectively represent the empirical cumulative distribution functions of investments in social media communications (SM) and investments in online advertising (OA). Significant S-K and Shapiro-Wilk tests reject the null hypothesis of normality for investments in both social media communication $(\mathrm{S}-\mathrm{K}$ test: $\mathrm{p}<.00$; Shapiro-Wilk test $\mathrm{p}<.00)$ and online advertising $(\mathrm{S}-\mathrm{K}$ test: $\mathrm{p}$ $<.00$; Shapiro-Wilk test $\mathrm{p}<.00$ ), showing non-normality in the data as required for identification. Models 5-8 in Table 4 demonstrate the regression results including the copula terms. A comparison of these endogeneity-corrected results (Models 5-8) with Models 1-4 demonstrates that all hypothesis tests yield the same conclusions. Hence, we are confident that omitted variables are unlikely to affect the results of our hypothesis tests.

\section{Discussion}

This study offers a response to calls — some over a decade old (e.g., Prins and Verhoef, 2007)— for contemporary explanations of new product success. To that end, the study focuses on likely effects of investments in social media communication and online advertising on new product sales volume and profits. The study's theoretical baseline is that reactance to product promotion messages is more likely to occur for online advertising than for social media communication. Exposure to product-related social media communication is voluntary while online advertising can be difficult to avoid and is usually seen as disrupting consumers' online activities. The results support this reasoning and highlight reactance theory as an important explanatory device for variations in new product success linked to investments in social media communication and online advertising.

In particular, the empirical findings show that investments in social media communication tend to have a positive but diminishing relationship with the sales volume and profits of a new product, which contrasts with an inverted U-shaped relationship for online advertising 
investments associated with the same product. The results also show that these relationships are dependent on how superior and consumer-engaging the new products are. For investments in online advertising, results indicate that the optimal communication investment level—which is reflected in the apex of the inverse U-shaped relationship with sales volume and profits_-is not only lower at higher levels of product involvement, but also shifts to the left. The reverse is the case for higher levels of product superiority, with the optimal amount of investment being higher than otherwise and shifted to the right, but only for new product sales, as new product profits remain uninfluenced by product superiority. For social media communication, results show that communication investments are more strongly linked to both the sales volume and profits of a new product if product involvement is high, while product superiority weakens the two links.

\section{Theoretical implications}

This is the first multi-firm study to analyze the sales volume and profit implications for new products that have been promoted during their launch phase simultaneously with social media communication and online advertising. Since the findings indicate that the success rates for new products differ notably across the two digital communication formats, future studies in this area should treat social media communication and online advertising investments separately and refrain from aggregating the two formats (see Table 1).

Further, this study extends the product innovation management literature by incorporating

predictions based on reactance theory. The results demonstrate that reactance theory can contribute to a deeper theoretical understanding of the complex processes underlying variations in new product success that are associated with differences in the promotional effectiveness of different digital communications formats. Future new product success studies with a digital communications perspective are likely to find reactance theory an important theoretical lens. 
This research also extends the conceptual perspective adopted by the majority of studies concerned with linking marketing communications to the fate of products in the marketplace. Most of those studies focus on identifying linear relationships (see Table 1). This study shows that taking a non-linear conceptual perspective facilitates fresh theoretical reasoning and new empirical insights in a new product launch context. Researchers should note, for instance, that above a certain level of online advertising investment, results reported in this study indicate that online advertising can become detrimental to the sales volume and profits of a newly launched product. To that end, the results demonstrate that large investments in online advertising for new products can become a liability. The findings also show that investments in social media communication are not without limitations, either. Although no detrimental sales volume and profit effects were observed, decreasing marginal returns at high levels of social media investment were detected. To uncover such findings, it is essential to go beyond linear conceptual perspectives.

The study also adds a new contingency perspective to the product innovation management literature. While research on the design of communication messages demonstrates that communications effects in general can hinge on product characteristics (e.g., Hultink and Robben, 1999), the moderating role of product characteristics has not been considered in studies concerned with digital communications effects. The findings of the present study related to social media communication and product superiority are especially noteworthy. Recall that product superiority weakens the link between social media investments and both the sales volume and profits of a new product. Those results contradict findings from research into traditional communications during product launches. For example, Frattini, Dell'Era, and Rangone (2013) observe that traditional communications exhibit a stronger impact on new 
product success for superior products. As presented earlier (see H3), there are theoretical arguments for and against a stronger relationship between investments in social media communication and new product success for superior products. The extent to which theoretical explanations may apply to both traditional and social media investments, therefore, remains an open question.

Finally, this study complements extant research on the role of social media in product innovation management. Moe and Schweidel (2017) note that the role of social media in the product innovation management literature is dichotomized as (1) an information tool for generating new product ideas and (2) a promotion tool. While most conceptual and empirical research has focused on the role of social media as an information tool, this study highlights the importance of research into social media communication as a promotion tool (e.g., Roberts and Candi, 2014).

\section{Managerial implications}

The findings reported in this article offer guidance to managers for promoting new products with social media communication and online advertising during the product launch phase. The interviews conducted with the 15 managers consulted for this study (see Method section) reveal a need for such guidance; most managers expressed uncertainty about which digital communications format best to invest in to support new products. As one manager from a large automobile brand put it: "When products are new, it is harder to go by what worked in the past, obviously. Combining our target's “media diet”, media planners' insights, and one's gut feeling for what works and what doesn't, that's what guides our media investments. It's often more feeling than science."

An important finding of this study to note is that managers should consider the divergent 
capacity of social media communication and online advertising to resonate with consumers when launching new products. While this study's results point to positive, but diminishing investment returns for social media communication, an inverted U-shaped relationship between investments in online advertising and new product success can also be observed. Thus, on average, social media communication appears to be more effective than online advertising for new product launches.

Interestingly, this empirical finding is not reflected in the actual communication investment levels found in this study's sample. Specifically, the surveyed managers made considerably smaller investments in social media communication $($ mean $=49.10)$ than in online advertising $($ mean $=59.43)($ see Table 3$)$. One interviewed marketing manager points to a possible reason for such investment differences: "It is not just the money you invest in social media, but the people and time to keep the media alive and dynamic. Social media is very involving if done well and drains resources ongoing. ",

Managers also need to consider that reactance effects to digital communication investments are likely to be especially pronounced for online advertising. Findings from this study suggest that reactance effects related to the properties of online advertising (see Table 2) can even erode new product sales volume and profits. Interestingly, such undesirable effects seem, at times, to be overlooked in business practice. A media consultant mentioned: "Some agencies just do not advise their clients to use frequency capping [technology that caps the number of times a specific visitor to a website is shown a particular online advertisement]. That is a shame because every time you go back to a site which you have already visited that day, the same pop-up or banner ad appears. The first and second time is fine, but then it will most certainly start to get on peoples' nerves". 
Calculating what the ideal investment levels in online advertising would be, the results show—at least for the firms in this study and in a new product context— that the well-known practitioner adage for traditional advertising, namely that "half of the money spent on advertising is wasted", also appears to ring true for online advertising. After back-transforming the meancentered data, the optimal investment level is 27.18 for sales volume and 33.88 for profits on the 0-100 scale used to measure online advertising investments in this study (see the independent variables section under the Measures heading). On average, however, companies in the sample invested 59.43, which is about twice what would constitute an optimal investment for online advertising. Inserting the two optimal investment levels $\left(\mathrm{OA}^{*}=33.88\right.$ and $\left.\mathrm{OA}_{\text {current }}=59.43\right)$ in the un-centered regression equations to calculate expected new product profits, the results indicate that, on average, managers would be able to reduce investments in online advertising by half while still increasing their new product profits by $10 \%$. At the same time, managers should also note that social media communication seems to be only marginally effective at high investment levels, which suggests that there is also an investment limit for this digital communications format.

Further, results suggest that managers need to account for product characteristics when investing in a new product's digital communications campaign. This study shows that managers responsible for promoting a new, durable product should note that the more consumer-involving the offering is, the higher the level of investment in online advertising is required to achieve a given sales volume and profit target, while social media communication investments can be wound back correspondingly. Managers also should be aware that the less superior a new product is, the more investments in social media communication and online advertising are likely to be required to achieve a specific sales volume and profit target. And in the case of a sales 
volume and profit maximization objective, results suggest that managers should consider shifting their communication investments from online advertising to social media, the less superior the new product is, bearing in mind the diminishing communication efficiency of social media at high investment levels.

Interestingly, the finding that social media communication is less effective for superior products is at odds with practitioner expectations regarding social media communication. One manager, for instance, expressed the following view: "If you are early or really innovative, social media is just the way to go. You will definitely find consumers out there who will want to talk about what's new about the product in this case and essentially end up doing your job, for free."

In conclusion, the reported results show that, on average, the sampled firms over-invested in online advertising and under-invested in social media for the promotion of new products. We call on researchers to provide more managerial guidance on how to optimize investments in social media communication and online advertising to promote new products.

\section{Limitations and Directions for Future Research}

This study must be qualified in several ways. First, the reported findings are based on data collected at a single point in time and — despite best efforts to include controls and endogeneitycorrection terms-cannot be used to establish causal relationships among the study's variables.

Second, the empirical analyses focused on consumer durables, hence the reported findings may not extend to other product categories. Thus, in terms of improving generalizability and establishing causality, one direction for future research is to confirm our findings in an experimental setting (Blake, Nosko, and Tadelis, 2015).

More research opportunities arise from possible extensions of the conceptual model. Given 
how prone online advertising appears to be to consumer reactance-as opposed to social media communication — and given that online advertising continues to feature prominently in firms' product promotion mixes, research into how to reduce online advertising-induced reactance to new product messages is in the interest of firms and consumers. For instance, an interesting research topic would be to build on explanations of why reactance is less likely to be associated with social media communication and explore whether, and to what extent, enabling consumers to gain control over product advertising online could reduce their reactance. One way to provide advertising control is a practice that can be observed on YouTube, which is to provide consumers with an option to skip a given online advertisement within a certain time period; how reactancestifling such an option is remains to be explored. In addition, whether there are differences in digital communications effectiveness for established products compared with new products is an open research question. Finally, other potentially interesting variables could be explored to enhance the study's findings. For example, additional new product characteristics, such as trialability, perceived complexity, and perceived risk suggested by Rogers (2003) might influence the presented results. Much remains to be investigated to fully understand how best to support product launches with digital communications.

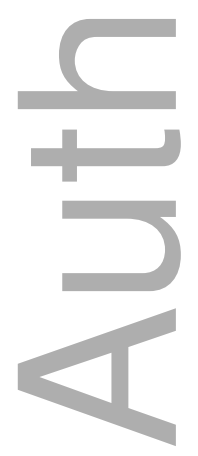




\section{References}

Aguinis, H., J. C. Beaty, R. J. Boik, and C. A. Pierce. 2005. Effect size and power in assessing moderating effects of categorical variables using multiple regression: A 30-year review. Journal of Applied Psychology 90(1): 94-107.

Armstrong, J. S., and T. S. Overton. 1977. Estimating nonresponse bias in mail surveys. Journal of Marketing Research 14(3): 396-402.

Bagozzi, R. P., and Y. Yi. 2012. Specification, evaluation, and interpretation of structural equation models. Journal of the Academy of Marketing Science 40(1): 8-34.

Barroso, A., and G. Llobet. 2012. Advertising and consumer awareness of new, differentiated products. Journal of Marketing Research 49(6): 773-792.

Blake, T., C. Nosko, and S. Tadelis. 2015. Consumer heterogeneity and paid search effectiveness: A large-scale field experiment. Econometrica 83(1): 155-174.

Brehm, J. W. 1966. A Theory of Psychological Reactance. New York: Academic Press.

Burmester, A. B., J. U. Becker, H. J. Van Heerde, and M. Clement. 2015. The impact of pre- and postlaunch publicity and advertising on new product sales. International Journal of Research in Marketing 32(4): 408-417.

Buss, D. 2013. Thanks To Fiesta, Ford Leads Retail Growth With Millennials. Available at: https://www.forbes.com/sites/dalebuss/2013/08/22/thanks-to-fiesta-ford-leads-retail-growthwith-millennials/\#1e20b8c43de7

Calantone, R. J., and C. A. Di Benedetto. 2012. The role of lean execution and launch timing on new product performance. Journal of the Academy of Marketing Science 40(4): 526-538.

Champoux, J. E., and W. S. Peters. 1987. Form, effect size and power in moderated regression analysis. Journal of Occupational Psychology 60(3): 243-255.

Cho, C., and H. J. Cheon. 2004. Why do people avoid advertising on the internet? Journal of Advertising 33(4): 89-97.

Clee, M. A., and R. A. Wicklund. 1980. Consumer behavior and psychological reactance. Journal of Consumer Research 6(4): 389-405.

Cooper, R., and U. De Brentani. 1991. New industrial financial services: What distinguishes the winners. Journal of Product Innovation Management 8(2): 75-90.

Dahl, D. 2013. Riding the Momentum Created by a Cheeky Video. Available at: https://www.nytimes.com/2013/04/11/business/smallbusiness/dollar-shave-club-from-viralvideo-to-real-business.html?pagewanted=alland_r=2and

Dahl, D. W., and S. Hoeffler. 2004. Visualizing the self: Explorig the potential benefits and drawbacks for new product evaluation. Journal of Product Innovation Management 21(4): 259-287.

Danaher, P. J., and T. S. Dagger. 2013. Comparing the relative effectiveness of advertising channels: A case study of a multimedia blitz campaign. Journal of Marketing Research 50(4): 517-534.

Daneshkhu, S. 2016. How Michael Dubin built Dollar Shave Club into a \$1bn Company. Available at: https://www.ft.com/content/2aca7c08-4e69-11e6-8172-e39ecd3b86fc

Datta, H., B. Foubert, and H. J. Van Heerde. 2015. The challenge of retaining customers acquired with free trials. Journal of Marketing Research 52(2): 217-234.

De Haan, E., T. Wiesel, and K. Pauwels. 2016. The effectiveness of different forms of online advertising for purchase conversion in a multiple-channel attribution framework. International Journal of Research in Marketing 33(3): 491-507.

Di Benedetto, C. A. 1999. Identifying the key success factors in new product launch. Journal of Product Innovation Management 16(6): 530-544.

Dinner, I. M., H. J. Van Heerde, and S. A. Neslin. 2014. Driving online and offline sales: The cross- 
channel effects of traditional, online display, and paid search advertising. Journal of Marketing Research 51(5): 527-545.

Du, S., G. Yalcinkaya, and L. Bstieler. 2016. Sustainability, social media driven open innovation, and new product development performance. Journal of Product Innovation Management 33(1): 5571.

Edwards, S. M., H. Li, and J. Lee. 2002. Forced exposure and psychological reactance: Antecedents and consequences of the perceived intrusiveness of pop-up ads. Journal of Advertising 31(3): 83-95.

Fornell, C., and D. F. Larcker. 1981. Structural equation models with unobservable variables and measurement error: Algebra and statistics. Journal of Marketing Research 18(3): 382-388.

Frattini, F., C. Dell'Era, and A. Rangone. 2013. Launch decisions and the early market survival of innovations: An empirical analysis for the italian value-added services (VAS) industry. Journal of Product Innovation Management 30(1): 174-187.

Füller, J., K. Matzler, and M. Hoppe. 2008. Brand community members as a source of innovation. Journal of Product Innovation Management 25(6): 608-619.

Gerbing, D. W., and J. C. Anderson. 1988. An updated paradigm for scale development incorporating unidimensionality and its assessment. Journal of Marketing Research 25(2): 186-192.

Godfrey, A., K. Seiders, and G. B. Voss. 2011. Enough is enough! The fine line in executing multichannel relational communication. Journal of Marketing 75(4): 94-109.

Goldfarb, A., and C. Tucker. 2011. Online display advertising: Targeting and obtrusiveness. Marketing Science 30(3): 389-404.

Gruner, R. L., C. Homburg, and B. A. Lukas. 2014. Firm-hosted online brand communities and new product success. Journal of the Academy of Marketing Science 42(1): 29-48.

Haans, R. F. J., C. Pieters, and Z. He. 2015. Thinking about U: Theorizing and testing U- and inverted U-shaped relationships in strategy research. Strategic Management Journal 37(7): 1177-1195.

HBR. 2017. Available at: https://hbr.org/2017/03/do-search-ads-really-work

Heidenreich, S., and M. Handrich. 2015. What about passive innovation resistance? Investigating adoption-related behavior from a resistance perspective. Journal of Product Innovation Management 32(6): 878-903.

Heidenreich, S., and T. Kraemer. 2016. Innovations - doomed to fail? Investigating strategies to overcome passive innovation resistance. Journal of Product Innovation Management 33(3): 277 297.

Hofstetter, R., S. Aryobsei, and A. Herrmann. 2018. Should you really produce what consumers like online? Empirical Evidence for reciprocal voting in open innovation contests. Journal of Product Innovation Management 35(2): 209-229.

Homburg, C., M. Klarmann, M. Reimann, and O. Schilke. 2012. What Drives Key Informant Accuracy? Journal of Marketing Research 49(4): 594-608.

Hultink, E. J., and H. S. J. Robben. 1995. Measuring new product success: The difference that time perspectives makes. Journal of Product Innovation Management 12(5): 392-405.

Hultink, E. J., and H. S. J. Robben. 1999. Launch strategy and new product performance: An empirical examination in the Netherlands. Journal of Product Innovation Management 16(6): 545-556.

Hultink, E. J., A. Griffin, S. Hart, and H. Robben. 1997. Industrial new product launch startegies and product development performance. Journal of Product Innovation Management 14(4): 243-257.

Hultink, E. J., A. Griffin, H. Robben, and S. Hart. 1998. In search of generic launch strategies for new products. International Journal of Research in Marketing 15(3): 269-285.

Horsky, D., and L. S. Simon. 1983. Advertising and the diffusion of new products. Marketing Science 2(1): 1-17.

This article is protected by copyright. All rights reserved 
Im, S., and J. P. Workman. 2004. Market orientation, creativity, and new product performance. Journal of Marketing 68(2): 114-132.

Kaplan, A. M., and M. Haenlein. 2010. Users of the world, unite! The challenges and opportunities of social media. Business Horizons 53(1): 59-68.

Kumar, A., R. Bezawada, R. Rishika, R. Janakiraman, and P. K. Kannan. 2016. From social to sale: the effects of firm-generated content in social media on customer behavior. Journal of Marketing 80(1): 7-25.

Langerak, F., E. J. Hultink, and A. Griffin. 2008. Exploring mediating and moderating influences on the links among cycle time, proficiency in entry timing, and new product profitability. Journal of Product Innovation Management 25(4): 370-385.

Laurent, G., and J.Kapferer. 1985. Measuring consumer involvement profiles. Journal of Marketing Research 22(1), 41-53.

Lee, S., K. J. Kim, and S. S. Sundar. 2015. Customization in location-based advertising: Effects of tailoring source, locational congruity, and product involvement on ad attitudes. Computers in Human Behavior 51(October): 336-343.

Lee, Y., and G. C. O'Connor. 2003. The impact of communication strategy on launching new products: The moderating role of product innovativeness. Journal of Product Innovation Management 20(1): 4-21.

Libai, B., E. Muller, and R. Peres. 2013. Decomposing the value of word-of-mouth seeding programs: Acceleration versus expansion. Journal of Marketing Research 50(2): 161-176.

Little, T. D., U. Lindenberger, and J. R. Nesselroade. 1999. On selecting indicators for multivariate measurement and modeling with latent variables: When "good" indicators are bad and "bad" indicators are good. Psychological Methods 4(2): 191-211.

Marion, T. J., G. Barczak, and E. J. Hultink. 2014. Do social media tools impact the development phase? An exploratory study. Journal of Product Innovation Management 31(S1): 18-29.

Miron, A. M., and J. W. Brehm. 2006. Reactance theory - 40 years later. Zeitschrift für Sozialpsychologie 37(1): 9-18.

Moe, W. W., and D. A. Schweidel. 2017. Opportunities for innovation in social media analytics. Journal of Product Innovation Management 51(4): 387-402.

Morgan, B. 2015. When brands try too hard on social media. Forbes, Retrieved from http://www.forbes.com/sites/blakemorgan/2015/08/31/when-brands-try-too-hard-on-socialmedia/\#571e138d41fe

Mulhern, F. 2009. Integrated marketing communications: From media channels to digital connectivity. Journal of Marketing Communications 15(2-3): 85-101.

Park, S., and S. Gupta. 2012. Handling endogenous regressors by joint estimation using copulas. Marketing Science 31(4): 567-586.

Parry, M. E., and T. Kawakami. 2014. Virtual word of mouth and willingness to pay for consumer electronic innovations. Journal of Product Innovation Management 32(2): 192-200.

Parry, M. E., T. Kawakami, and K. Kishiya. 2012. The effect of personal and virtual word-of-mouth on technology acceptance. Journal of Product Innovation Management 29(6): 952-966.

Petty, R. E., J. T. Cacioppo, and D. Schumann. 1983. Central and peripheral routes to advertising effectiveness: The moderating role of involvement. Journal of Consumer Research 10(2): 135146.

Piskorski, M. J. 2014. A social strategy: How we profit from social media. Princeton University Press.

Podsakoff, P. M., S. B. MacKenzie, and N. P. Podsakoff. 2012. Sources of method bias in social science research and recommendations on how to control it. Annual Review of Psychology 63(1): 539-

This article is protected by copyright. All rights reserved 
569.

Prins, R., and P. C. Verhoef. 2007. Marketing communication drivers of adoption timing of a new eservice among existing customers. Journal of Marketing 71(2): 169-183.

Ram, S., and J. N. Sheth. 1989. Consumer resistance to innovations: The marketing problem and its solutions. Journal of Consumer Marketing 24(7): 419-427.

Richard, P. J., T. M. Devinney, G. S. Yip, and G. Johnson. 2009. Measuring organizational performance: Towards methodological best practice. Journal of Management 35(3): 718-804.

Roberts, D. L., and M. Candi. 2014. Leveraging social network sites in new product development: Opportunity or hype? Journal of Product Innovation Management 31(1): 105-117.

Roberts, D. L., and F. Piller. 2016. Finding the right role for social media in innovation. MIT Sloan 57(3): 41-47.

Roberts, D. L., F. Piller, and D. Lüttgens. 2016. Mapping the impact of social media for innovation: The role of social media in explaining innovation performance in the PDMA comparative performance assessment study. Journal of Product Innovation Management 33(1): 117-135.

Robertson, T. S., and J. R. Rossiter. 1974. Children and commercial persuasion: An attribution theory analysis. Journal of Consumer Research 1(1): 13-20.

Rogers, E. K. 2003. Diffusion of Innovations. (5th ed). New York: Free Press.

Russell, C. J., and P. Bobko. 1992. Moderated regression analysis and Likert scales: Too coarse for comfort. Journal of Applied Psychology 77(3): 336-342.

Spenner, P. 2010. Why You Need a New-Media Ringmaster. Harvard Business Review. 88(12): 78-79.

Srinivasan, S., O. J. Rutz, and K. Pauwels. 2016. Paths to and off purchase: Quantifying the impact of traditional marketing and online consumer activity. Journal of the Academy of Marketing Science 44(4): 440-453.

Statista. 2018. Available at: https://www.statista.com/outlook/216/100/digitaladvertising/worldwide\#market-revenue. Accessed 15.06.18.

Steenkamp, J. B. E. M., and K. Gielens. 2003. Consumer and market drivers of the trial probability of new consumer packaged goods. Journal of Consumer Research 30(3): 368-384.

Storey, C., and C. Easingwood. 1998. The augmented service offering: A conceptualization and study of its impact on new service success. Journal of Product Innovation Management 15(4): 335-351.

Talke, K., and G. C. O'Connor. 2011. Conveying effective message content when launching new industrial products. Journal of Product Innovation Management 28(6): 943-956.

Talke, K., and E. J. Hultink. 2010. Managing diffusion barriers when launching new products. Journal of Product Innovation Management 27(4): 537-553.

Talke, K., and D. Snelders. 2013. Information in launch messages: Stimulating the adoption of new high-tech consumer products. Journal of Product Innovation Management 30(4): 732-749.

Turow, J., J. King, C. J. Hoofnagle, A. Bleakley, and M. Hennessy. 2009. Americans reject tailored advertising and three activities that enable it. Working paper. Available at: http://dx.doi.org/10.2139/ssrn.1478214

Wall, T. D., J. Michie, M. Patterson, S. J. Wood., M. Sheehan, C. W. Clegg, and M. West. 2004. On the validity of subjective measures of company performance. Personnel Psychology 57(1): 95-118.

Westbrook, R. A. 1987. Product/consumption-based affective responses and postpurchase processes. Journal of Marketing Research 24(3): 258-270.

Winer, R. S. 2009. New communications approaches in marketing: Issues and research directions. Journal of Interactive Marketing 23(2): 108-117.

Zaichkowsky, J. L. 1985. Measuring the involvement construct. Journal of Consumer Research 12(3): 341-352.

This article is protected by copyright. All rights reserved 


\section{Endnotes}

${ }^{1}$ Updated sales figures have not been released in the press since Unilever's acquisition.

${ }^{2}$ Products were considered as established unless explicitly qualified as "new" in a given study.

${ }^{3}$ Haans, Pieters, and He (2015) show that inverted U-shaped relationships resemble the net effects of, for instance, a positive and linear effect and a countervailing convex effect. In this study's context, the awarenessand preference-creating effects of online advertising approximate the positive and linear effect. The study's conclusions would remain unaffected if one assumed a concave relationship. Since reactance tends to increase slowly in the beginning, but then escalate, the negative effects of reactance can be approximated by a convex relationship.

${ }^{4}$ Generally, moderating effects of inverted U-shaped relationships can occur in two distinct ways. First, the moderator can shift the ideal point to the left or the right. Second, the moderator can steepen or flatten the shape of the inverted U-shaped relationship. Haans, Pieters, and He (2015) show mathematically that if the moderator strengthens the negative effect pertaining to the inverted U-shaped relationship, the overall shape becomes steeper.

${ }^{5}$ The managers were interviewed for multiple research studies planned by the authors involving different datasets (e.g., Gruner, Homburg, and Lukas, 2014).

${ }^{6} \mathrm{~A}$ wide-range rating scale can be challenging for respondents and may offset the benefit of a fine-grained evaluation option. However, the distribution of the respondents' ratings shows no reason for concern.

${ }^{7}$ The possibility that a new product may be strongly/prominently positioned in terms of dependability, durability, and convenience propositions has to be accounted for, because such value propositions are commonly used for durable goods as they are known to be linked to product success. Note that such positioning does not necessarily mean that a product embodies something superior, such as game-changing technology, an unrivaled benefit over competitor products, or excellence in aesthetic features, as captured by the product superiority measure.

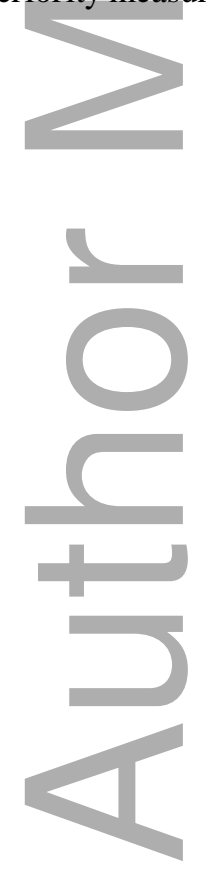


Figure 1: Conceptual Model and Data Sources

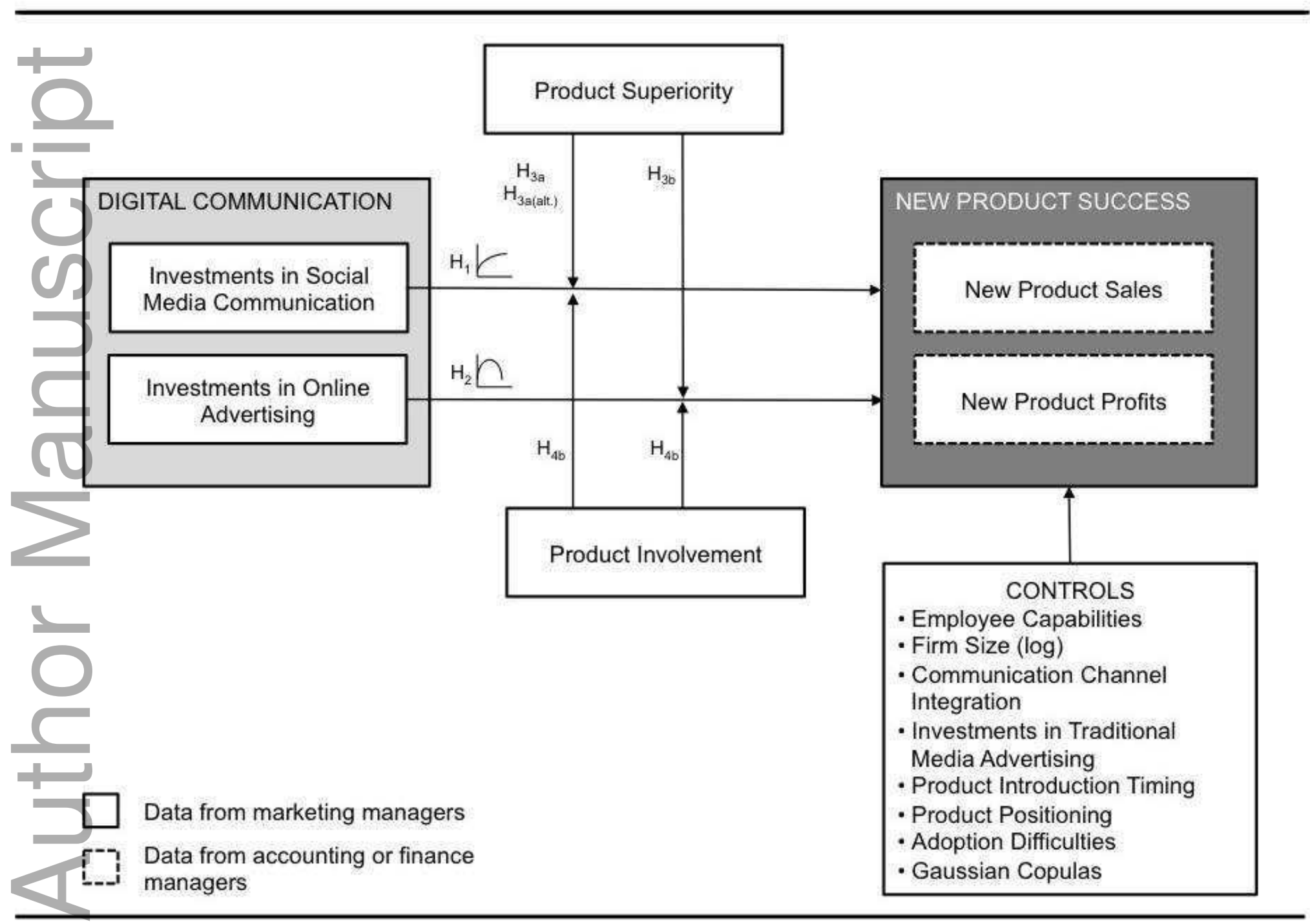

This article is protected by copyright. All rights reserved 
Table 1. A Review of New Product Studies Concerned with Communications (Traditional and Digital)

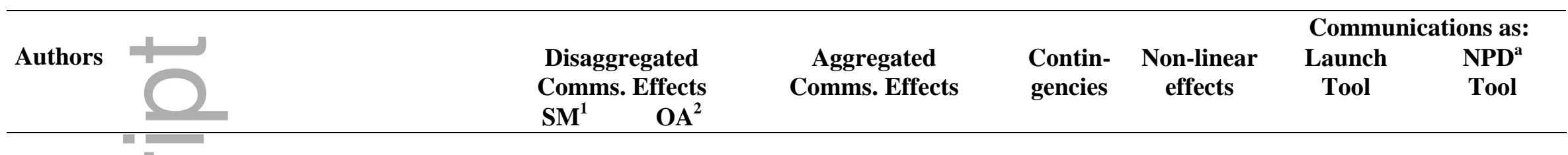

1. Selected studies on the aggregated effects of traditional and digital communications

Barroso and Llobet (2012)

Calantone and Di Benedetto (2012)

Cooper and De Brentani (1991)

Di Benedetto (1999)

Frattini, Dell'Era, and Rangone (2013)

Hultink et al. (1997)

Hultink et al.(1998)

Hultink and Robben (1999)

Prins and Verhoef (2007)

Steenkamp and Gielens (2003)

Storey and Easingwood (1998)

$\begin{array}{ccc}\text { Mass media } & - & X \\ \text { Overall measure } & - & - \\ \text { Overall measure } & - & - \\ \text { Mass media } & - & - \\ \text { Mass media incl. digital } & \mathrm{X} & - \\ \text { Not specified } & - & - \\ \text { Mass media and direct } & - & - \\ \text { Mass media and direct } & \mathrm{X} & - \\ \text { Mass media and direct } & - & - \\ \text { Mass media } & - & - \\ \text { Not specified } & - & -\end{array}$

\begin{tabular}{ll}
$X$ & - \\
$X$ & - \\
$X$ & - \\
$X$ & - \\
$X$ & - \\
$X$ & - \\
$X$ & - \\
$X$ & - \\
$X$ & - \\
$X$ & - \\
$X$ & - \\
& \\
- & $X$ \\
- & $X$ \\
- & $X$ \\
\hline$X$ & $X$ \\
- & $X$ \\
$X$ & -
\end{tabular}

2. Selected studies on the disaggregated effects of digital communications

Du, Yalcinkaya, and Bstieler (2016)

Füller, Matzler, and Hoppe (2008)

Hofstetter, Aryobsei, and Herrmann (2018)

Marion, Barczak, and Hultink (2014)

Roberts and Candi (2014)

Roberts, Piller, and Lüttgens (2016)

\section{This study}

$\begin{array}{ll}X & - \\ X & - \\ X & - \\ X & - \\ X & - \\ X & - \\ X & X\end{array}$

${ }^{a}$ An example of a NPD tool is the use of social media communication as an idea source for new products or product features.

Notes: X included in the reviewed study; — not included in the reviewed study. ${ }^{1}$ Social media (SM) communication; ${ }^{2}$ online advertising (OA). The category of

"aggregated effects" refers to studies that do not separate the effects of different communication formats in their empirical analyses, thereby treating

communications as an aggregate construct.

This article is protected by copyright. All rights reserved 


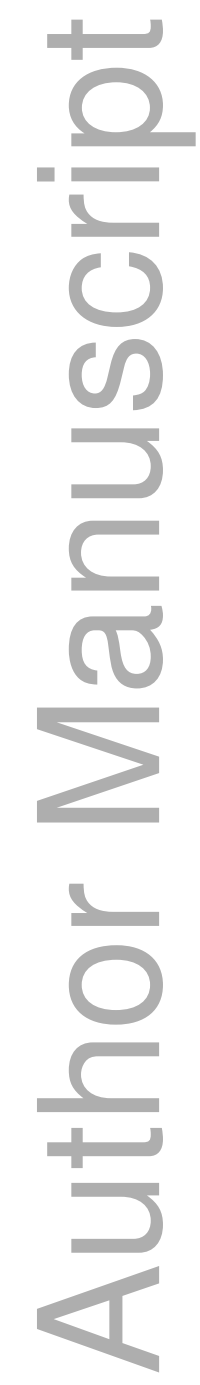

This article is protected by copyright. All rights reserved 
Table 2. Comparison of Social Media Communication and Online Advertising

\begin{tabular}{|c|c|c|c|}
\hline ك-10 & $\begin{array}{c}\text { Communication } \\
\text { initiation }\end{array}$ & $\begin{array}{c}\text { Communication } \\
\text { control }\end{array}$ & $\begin{array}{c}\text { Communication } \\
\text { intrusiveness }\end{array}$ \\
\hline
\end{tabular}

Social Media

Communication:

Both firm and consumer can

initiate the communication

Firm initiates the

Online

Advertising:

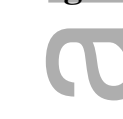

communication
Owned media: Firm controls communication content

Earned media: Firm

relinquishes control over

communication content

$+$

Paid media: Firm controls

advertising content

Generally unintrusive (could become intrusive when topic saturation sets in)

Notes: Social media communication includes brand community communication, social network communication, and video sharing. Online advertising includes display advertising and search engine advertising.

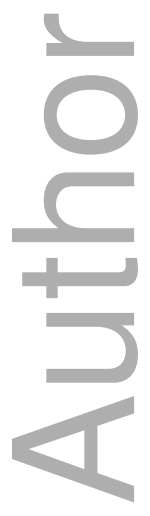

This article is protected by copyright. All rights reserved 
Table 3. Descriptive Statistics and Correlations

\begin{tabular}{|c|c|c|c|c|c|c|c|c|c|c|c|c|c|c|c|c|c|c|c|}
\hline & & $\mathbf{M}$ & SD & AVE & CR & $\mathbf{C A}$ & 1 & 2 & 3 & 4 & 5 & 6 & 7 & 8 & 9 & 10 & 11 & 12 & 13 \\
\hline 1 & New product sales volume & 5.13 & 1.58 & .81 & .93 & .93 & .90 & & & & & & & & & & & & \\
\hline 2 & New product profits & 4.81 & 1.54 & .83 & .93 & .94 & $.81^{*}$ & .91 & & & & & & & & & & & \\
\hline 3 & Social media communication & 49.10 & 25.80 & .71 & .93 & .94 & $.48 *$ & $.40 *$ & .84 & & & & & & & & & & \\
\hline 4 & Online advertising & 59.43 & 19.92 & .65 & .92 & .91 & $-.31 *$ & $-.34 *$ & .08 & .80 & & & & & & & & & \\
\hline 5 & Traditional media advertising & 55.89 & 17.76 & .57 & .89 & .87 & $.23^{*}$ & .12 & $.29 *$ & $.27 *$ & .75 & & & & & & & & \\
\hline 6 & Employee capabilities & 5.95 & .80 & .59 & .88 & .90 & $.27 *$ & $.23^{*}$ & $.22 *$ & .15 & $.37 *$ & .77 & & & & & & & \\
\hline 7 & Product introduction timing & 3.92 & 2.02 & .87 & .93 & .93 & $.31^{*}$ & $.19^{*}$ & .06 & -.05 & $.25^{*}$ & $.21 *$ & .94 & & & & & & \\
\hline 8 & Communication channel integration & 4.83 & 1.23 & .80 & .94 & .93 & $.53 *$ & $.38^{*}$ & $.24 *$ & -.05 & $.38^{*}$ & $.25^{*}$ & $.19^{*}$ & .90 & & & & & \\
\hline 9 & Product positioning & 5.31 & 1.12 & .57 & .79 & .79 & $.46^{*}$ & $.36^{*}$ & $.27 *$ & .13 & $.20 *$ & $.37 *$ & $.26^{*}$ & $.33 *$ & .75 & & & & \\
\hline 10 & Adoption difficulties & 3.13 & 1.56 & .84 & .94 & .95 & .02 & -.02 & -.01 & .12 & .06 & .08 & $.26^{*}$ & .05 & .10 & .92 & & & \\
\hline 11 & Firm size $(\log )$ & 5.83 & 1.67 & - & - & - & .01 & .04 & .04 & .06 & -.12 & -.09 & -.08 & -.06 & -.03 & -.07 & - & & \\
\hline 12 & Product involvement & 5.50 & 1.27 & .76 & .93 & .93 & $.26^{*}$ & $.24 *$ & .04 & .03 & .16 & $.22 *$ & $.19^{*}$ & $.32 *$ & $.30^{*}$ & $.26^{*}$ & -.16 & .87 & \\
\hline 13 & Product superiority & 4.53 & 1.79 & .80 & .92 & .93 & $.29 *$ & $.30 *$ & .07 & -.09 & $.33 *$ & $.22 *$ & $.54 *$ & $.21 *$ & $.29 *$ & $.49^{*}$ & -.15 & $.35^{*}$ & .89 \\
\hline
\end{tabular}

$* \mathrm{p}<.05$

Notes: Mean value (M), standard deviation (SD), average variance extracted (AVE), composite reliability (CR), and Cronbach's alpha (CA); on the diagonal, we display the square root of the AVE. For the investment in social media communication, we report mean and standard deviation on the original scale because these values are interesting to compare with the levels of investment in online advertising. However, in line with our empirical models, correlations are based on the log-value of the investment in social media.

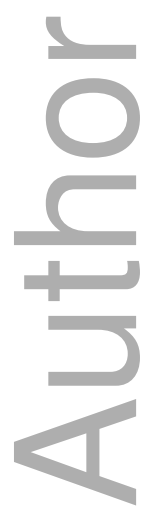

This article is protected by copyright. All rights reserved 
Table 4. Effects of Social Media Communication and Online Advertising on Perceived New Product Sales and Profits $(\mathrm{N}=$ 122)

\begin{tabular}{|c|c|c|c|c|c|c|c|c|c|c|}
\hline & & & Sales & Profits & Sales & Profits & Sales & Profits & Sales & Profits \\
\hline & & & Model 1 & Model 2 & Model 3 & Model 4 & Model 5 & Model 6 & Model 7 & Model 8 \\
\hline Constant & & & $5.337 * * *$ & $5.098 * * *$ & $5.319 * * *$ & $5.082 * * *$ & $5.441 * * *$ & $5.213^{* * *}$ & $5.473 * * *$ & $5.247 * * *$ \\
\hline \multicolumn{11}{|l|}{ Controls and moderators } \\
\hline Employee capabilities & & & .113 & $.211^{*}$ & .143 & $.220 *$ & .077 & .174 & .090 & .166 \\
\hline Firm size $(\log )$ & & & .060 & $.079 *$ & .060 & $.075^{*}$ & .059 & $.078^{*}$ & .052 & .067 \\
\hline Communication channel integration & & & $.277 * * *$ & .092 & $.324 * * *$ & $.131 *$ & $.281 * * *$ & .094 & $.332 * * *$ & $.139 *$ \\
\hline Traditional media advertising & & & -.004 & $-.012 * *$ & -.004 & $-.013 * *$ & -.003 & $-.011^{*}$ & -.003 & $-.012 *$ \\
\hline Product introduction timing & & & $.123 * * *$ & .011 & $.109 * *$ & -.013 & $.144 * * *$ & .029 & $.136^{* * *}$ & .011 \\
\hline Adoption difficulties & & & .012 & -.071 & -.002 & -.091 & .022 & -.061 & .014 & -.076 \\
\hline Product positioning & & & $.334 * * *$ & $.239 * * *$ & $.272 * * *$ & $.193 * *$ & $.326 * * *$ & $.242 * * *$ & $.255^{* * *} *$ & $.187 * *$ \\
\hline Product superiority & & & -.016 & $.149 * *$ & .094 & $.234 * * *$ & -.030 & $.137 * *$ & .074 & $.217 * * *$ \\
\hline Product involvement & & & .095 & $.136^{*}$ & -.105 & -.081 & $.103 *$ & $.143 * *$ & -.105 & -.086 \\
\hline \multicolumn{11}{|l|}{ Independent variables } \\
\hline Social media comm. $(\log )(\mathrm{SM})$ & $\mathrm{H}_{1}$ & $(\checkmark)$ & $.612 * * *$ & $.532 * * *$ & $.700 * * *$ & $.588 * * *$ & $.422 * *$ & $.453 * *$ & $.500 * *$ & $.495 * *$ \\
\hline Online advertising (OA) & & & $-.035 * * *$ & $-.037 * * *$ & $-.032 * * *$ & $-.031 * * *$ & $-.096 * * *$ & $-.101 * * *$ & $-.114 * * *$ & $-.117 * * *$ \\
\hline Online advertising (sq.) $\left(\mathrm{OA}^{2}\right)$ & $\mathrm{H}_{2}$ & $(\checkmark)$ & $-.001 * * *$ & $-.001 * * *$ & $-.000 * *$ & $-.001 * * *$ & $-.001 * * *$ & $-.001 * * *$ & $-.001 * * *$ & $-.001 * * *$ \\
\hline \multicolumn{11}{|l|}{ Interaction terms } \\
\hline SM x Product superiority & $\mathrm{H}_{3 \mathrm{a} \text { (alt.) }}$ & $(\checkmark)$ & & & $-.261 * * *$ & $-.260 * * *$ & & & $-.251 * * *$ & $-.249 * * *$ \\
\hline OA x Product superiority & & & & & $-.004 *$ & .000 & & & $-.005^{*}$ & -.000 \\
\hline $\mathrm{OA}^{2} \mathrm{x}$ Product superiority & $\mathrm{H}_{3 \mathrm{~b}}$ & (partial) & & & $-.000 * *$ & -.000 & & & $-.000 *$ & -.000 \\
\hline SM x Product involvement & $\mathrm{H}_{4 \mathrm{a}}$ & $(\checkmark)$ & & & $.390 * * *$ & $.403 * * *$ & & & $.423 * * *$ & $.435 * * *$ \\
\hline OA $x$ Product involvement & & & & & $.007 *$ & .004 & & & $.007 *$ & .004 \\
\hline $\mathrm{OA}^{2} \mathrm{x}$ Product involvement & $\mathrm{H}_{4 \mathrm{~b}}$ & $(\checkmark)$ & & & $.000 * * *$ & $.000 * * *$ & & & $.000 * * *$ & $.000 * * *$ \\
\hline Gaussian copulas & & & & & & & Included & Included & Included & Included \\
\hline $\mathrm{R}^{2}\left(\Delta \mathrm{R}^{2}\right)$ & & & $.62(-)$ & $.52(-)$ & $.67(.05 * *)$ & $.58(.06 * *)$ & $.64(-)$ & $.54(-)$ & $.69\left(.05^{* *}\right)$ & $.60\left(.06^{* *}\right)$ \\
\hline
\end{tabular}

$* \mathrm{p}<.10 ; * * \mathrm{p}<.05 ; * * * \mathrm{p}<.01$

Notes: Since our coefficients are mean-centered, in contrast to standardized coefficients, the sizes of the squared coefficients appear small due to the underlying scale. In Models 1-4, we test our hypotheses. Models 5-8 contain Gaussian copulas for investment in social media communication and online advertising to account for potentially omitted variables. Models 1-4 and Models 5-8 display similar results, indicating that omitted variables are unlikely to affect the results.

This article is protected by copyright. All rights reserved 


\section{APPENDIX}

Table A1. Abbreviated Measurement Items, Standardized Item Loadings (IL), and Item Reliabilities (IR)

\begin{tabular}{|c|c|c|c|c|}
\hline \multirow{2}{*}{$\begin{array}{l}\text { Construct name and items } \\
\text { New product sales volume and profits (adopted from Im and } \\
\text { Workman 2004) }\end{array}$} & \multicolumn{2}{|c|}{$\mathbf{I L}^{\mathbf{a}}$} & \multicolumn{2}{|c|}{$\mathbf{I R}^{\mathbf{a}}$} \\
\hline & Sales & Profits & Sales & Profits \\
\hline \multicolumn{5}{|l|}{ High sales/profits } \\
\hline - $\quad$ Relative to firm's other product launches & .94 & .92 & .88 & .84 \\
\hline - $\quad$ Relative to main competing products & .85 & .88 & .72 & .77 \\
\hline - $\quad$ Relative to product objectives & .92 & .93 & .85 & .86 \\
\hline \multirow{3}{*}{\multicolumn{5}{|c|}{$\begin{array}{l}\text { Investments in social media communication (SM) } \\
\text { Investments in online advertising (OA) } \\
\text { Compared with your main competitor in the market, this } \\
\text { product launch was supported by high levels of ... }\end{array}$}} \\
\hline & & & & \\
\hline & & & & \\
\hline $\begin{array}{l}\text { Development expenditure (committed to SM/OA } \\
\text { content) }\end{array}$ & .88 & .81 & .77 & .66 \\
\hline - $\quad$ Staff numbers (committed to SM/OA execution) & .93 & .79 & .86 & .62 \\
\hline - $\quad$ Staff hours (committed to SM/OA execution) & .89 & .79 & .79 & .62 \\
\hline \multicolumn{5}{|l|}{$\begin{array}{l}\text { Compared with firm's last product launch, this product launch } \\
\text { was supported by high levels of ... }\end{array}$} \\
\hline $\begin{array}{l}\text { - Development expenditure (committed to SM/OA } \\
\text { content) }\end{array}$ & .74 & .78 & .55 & .61 \\
\hline - $\quad$ Staff numbers (committed to SM/OA execution) & .84 & .85 & .71 & .72 \\
\hline - Staff hours (committed to SM/OA execution) & .74 & .80 & .55 & .64 \\
\hline
\end{tabular}

Product superiority (adopted from Lee and O'Connor 2003)

For customers the product has highly superior ...

- Technology $\quad .83$

- Benefits

- Features

Product involvement (adopted from Laurent and Kapferer 1985; Zaichkowsky 1985)

For customers the product commands high (much) ...

- Involvement

- Importance

- Care of choice

- Purchase thought

Investments in traditional media advertising (TM)

Compared with largest competitor's latest product, high ...

- Development expenditure (committed to TM content)

- Staff numbers (committed to TM execution)

- $\quad$ Staff hours (committed to TM execution)

Compared with firm's last product, high ... 


\begin{tabular}{llc}
\hline Construct name and items & $\mathbf{I L}^{\mathbf{a}}$ & $\mathbf{I R}^{\mathbf{a}}$ \\
\hline$\bullet \quad$ Development expenditure (committed to TM content) & .80 & .64 \\
$-\quad$ Staff numbers (committed to TM execution) & .75 & .56 \\
$-\quad$ Staff hours (committed to TM execution) & .77 & .59 \\
\hline
\end{tabular}

Communication channel integration (adapted from Mulhern

2009)

For the advertising campaign, high ...

- Cross-channel coordination

$.81 \quad .66$

- Amount of channels

$.93 \quad .86$

- Multi-channel content consistency $\quad .92 \quad .85$

- Communication platform synergy

$.92 \quad .85$

\section{Product positioning}

Positioned in terms of ...

- Dependability

- Convenience

$\begin{array}{ll}.77 & .59\end{array}$

- Durability

Adoption difficulties (adopted from Lee and O'Connor, 2003)

Customers need ...

- New knowledge to use this product

$.91 \quad .83$

- To learn how to use this new product

$.88 \quad .77$

- To change their behavior in order to adopt this product

$.96 \quad .92$

Employee capabilities (adopted from Di Benedetto 1999)

Abilities and skills, strong in ...

- Marketing research

$.75 \quad .56$

- Selling

$.84 \quad .71$

- Product distribution

$.81 \quad .66$

- Promotion

.76

.58

- $\quad \mathrm{R} \& \mathrm{D}$

.68

.46

Product introduction timing (adopted from Lee and

O'Connor 2003)

The new product can be characterized as ...

$\begin{array}{llll}- & \text { Early-mover } & .91 & .83\end{array}$

-
-

${ }^{\text {a }}$ Standardized item loadings (IL) represent the square roots of item reliabilities (IR) (Bagozzi and Yi 2012).

${ }^{\mathrm{b}}$ Loading below threshold value (Bagozzi and Yi 2012). However, deleting this item does not affect the regression estimations.

This article is protected by copyright. All rights reserved 


\section{APPENDIX}

Figure A1: Effect of Investments in Online Advertising on New Product Sales Volume (Panel A) and New Product Profits (Panel B)
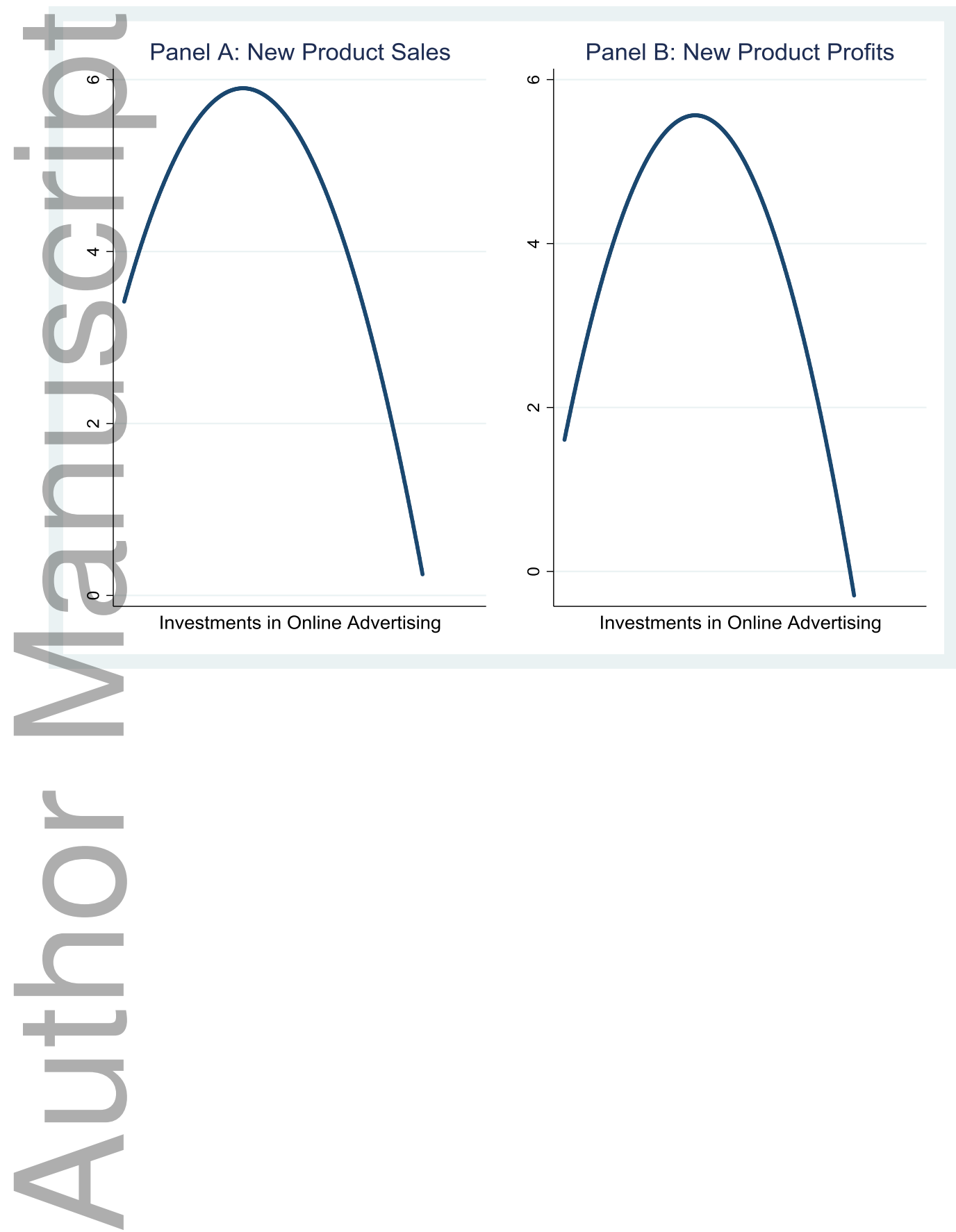


\section{APPENDIX}

\section{Figure A2: Moderating Effects for Investments in Online Advertising}

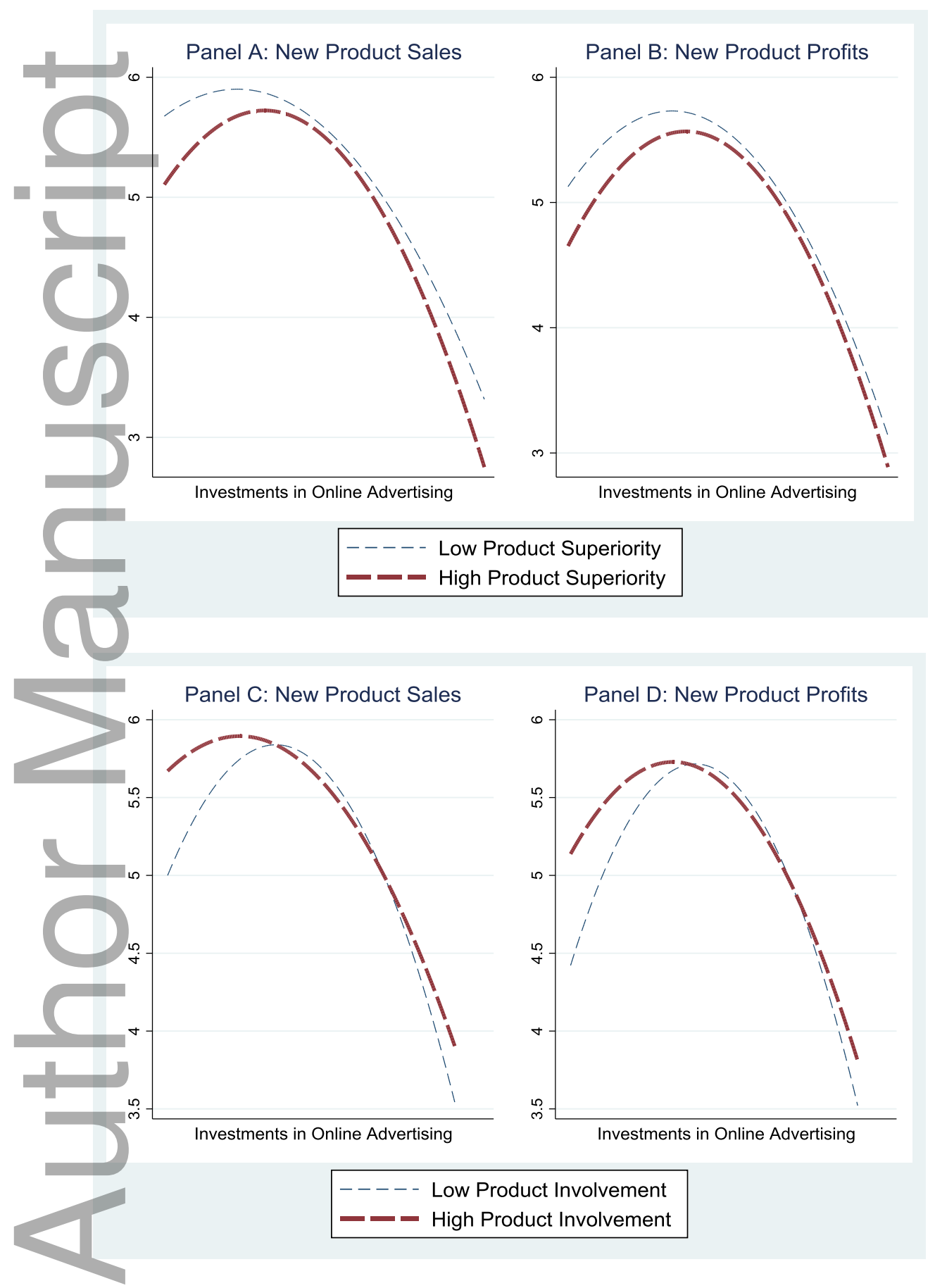

Notes: Product superiority shifts the optimal level of investments in online advertising to the right and steepens the inverted U-shaped relationship with new product sales (Panel A) $\left(\mathrm{H}_{3 a(a l t .)}\right)$. However, we observe no (significant) effect for new product profits (Panel B) $\left(\mathrm{H}_{3 \mathrm{~b}}\right)$. Product involvement shifts the optimal level of investments in online advertising to the left and flattens the inverted U-shaped relationship with new product sales (Panel C) $\left(\mathrm{H}_{4 \mathrm{a}}\right)$.and new product profits (Panel D) $\left(\mathrm{H}_{4 \mathrm{~b}}\right)$. 


\section{University Library}

\section{- M I N E R VA}

\section{A gateway to Melbourne's research publications}

Minerva Access is the Institutional Repository of The University of Melbourne

\section{Author/s:}

Gruner, RL;Vomberg, A;Homburg, C;Lukas, BA

Title:

Supporting New Product Launches With Social Media Communication and Online Advertising: Sales Volume and Profit Implications

\section{Date:}

2019-03-01

\section{Citation:}

Gruner, R. L., Vomberg, A., Homburg, C. \& Lukas, B. A. (2019). Supporting New Product Launches With Social Media Communication and Online Advertising: Sales Volume and Profit Implications. JOURNAL OF PRODUCT INNOVATION MANAGEMENT, 36 (2), pp.172-195. https://doi.org/10.1111/jpim. 12475.

Persistent Link:

http://hdl.handle.net/11343/284643 